\title{
Pou4f1 Defines a Subgroup of Type I Spiral Ganglion Neurons and Is Necessary for Normal Inner Hair Cell Presynaptic $\mathrm{Ca}^{2+}$ Signaling
}

\author{
Hanna E. Sherrill, ${ }^{1,2 *}$-Philippe Jean, ${ }^{3,4,5 *}$ Elizabeth C. Driver, ${ }^{1}$ Tessa R. Sanders, ${ }^{1}$ Tracy S. Fitzgerald, ${ }^{6}$ \\ Tobias Moser, ${ }^{3,5,7 \dagger}$ and Matthew W. Kelley ${ }^{1 \dagger}$ \\ ${ }^{1}$ Laboratory of Cochlear Development, National Institute on Deafness and Other Communication Disorders, National Institutes of Health, Bethesda, \\ Maryland 20892, ${ }^{2}$ Department of Neuroscience and Brown Institute for Brain Science, Brown University, Providence, Rhode Island 02912, ${ }^{3}$ Institute for \\ Auditory Neuroscience and Inner Ear Laboratory, University Medical Center Göttingen, 37073 Göttingen, Germany, ${ }^{4}$ Göttingen Graduate School for \\ Neurosciences and Molecular Biosciences, University of Göttingen, 37073 Göttingen, Germany, ${ }^{5}$ Auditory Neuroscience Group, Max Planck Institute for \\ Experimental Medicine, 37075 Göttingen, Germany, ${ }^{6}$ Mouse Auditory Testing Core Facility, National Institute on Deafness and Other Communication \\ Disorders, Bethesda, Maryland 20892, and ${ }^{7}$ Center for Nanoscale Microscopy and Molecular Physiology of the Brain, University of Göttingen, 37075 \\ Göttingen, Germany
}

Acoustic signals are relayed from the ear to the brain via spiral ganglion neurons (SGNs) that receive auditory information from the cochlear inner hair cells (IHCs) and transmit that information to the cochlear nucleus of the brainstem. Physiologically distinct classes of SGNs have been characterized by their spontaneous firing rate and responses to sound and those physiological distinctions are thought to correspond to stereotyped synaptic positions on the IHC. More recently, single-cell profiling has identified multiple groups of SGNs based on transcriptional profiling; however, correlations between any of these groups and distinct neuronal physiology have not been determined. In this study, we show that expression of the POU (Pit-Oct-Unc) transcription factor Pou4f1 in type I SGNs in mice of both sexes correlates with a synaptic location on the modiolar side of IHCs. Conditional deletion of Pou4f1 in SGNs beginning in mice at embryonic day 13 rescues the early path-finding and apoptotic phenotypes reported for germline deletion of Pou $4 f 1$, resulting in a phenotypically normal development of SGN patterning. However, conditional deletion of Pou4f1 in SGNs alters the activation of Ca ${ }^{2+}$ channels in IHCs primarily by increasing their voltage sensitivity. Moreover, the modiolar to pillar gradient of active zone Ca ${ }^{2+}$ influx strength is eliminated. These results demonstrate that a subset of modiolar-targeted SGNs retain expression of Pou4f1 beyond the onset of hearing and suggest that this transcription factor plays an instructive role in presynaptic $\mathrm{Ca}^{2+}$ signaling in IHCs.

Key words: cochlea; ear; hearing; synaptogenesis

Significance Statement

Physiologically distinct classes of type I spiral ganglion neurons (SGNs) are necessary to encode sound intensities spanning the audible range. Although anatomical studies have demonstrated structural correlates for some physiologically defined classes of type I SGNs, an understanding of the molecular pathways that specify each type is only now emerging. Here, we demonstrate that expression of the transcription factor Pou4f1 corresponds to a distinct subgroup of type I SGNs that synapse on the modiolar side of inner hair cells. The conditional deletion of Pou4f1 after SGN formation does not disrupt ganglion size or morphology, change the distribution of IHC synaptic locations, or affect the creation of synapses, but it does influence the voltage dependence and strength of $\mathrm{Ca}^{2+}$ influx at presynaptic active zones in inner hair cells.

\section{Introduction}

In mammals, cochlear inner hair cells (IHCs) convert pressure waves into electrochemical signals that are relayed to the brain via type I spiral ganglion neurons (SGNs). To encode a broad dynamic range of sounds, multiple categories of type I SGNs, each

the paper; P.J., T.M., and M.W.K. edited the paper; P.J., T.M., and M.W.K. wrote the paper; E.C.D. contributed unpublished reagents/analytic tools.

This work was supported by the Intramural Research Program of the National Institutes of Health-National Institute on Deafness and Other Communication Disorders (Grant DC000059 to M.W.K.), the German Research 
with distinct physiological properties, innervate each IHC. Although the full extent of SGN diversity is poorly understood, individual neurons can be classified based on their spontaneous firing rate, threshold of activation, and, more recently, transcriptional profile (Petitpré et al., 2018; Shrestha et al., 2018; Sun et al., 2018). Based on physiological properties, three type I SGNs, high-, medium-, and low-spontaneous rate, have been described in several species (Liberman, 1978; Winter et al., 1990; Taberner and Liberman, 2005). In addition, the firing properties of individual SGNs correlate with synaptic location on the base of each IHC. SGNs with low spontaneous rates and high thresholds are located on the medial (modiolar) sides of IHCs opposing active zones (AZs) with larger and, in some instances, multiple synaptic ribbons and stronger maximal $\mathrm{Ca}^{2+}$ influx that operates in a more depolarized range. In contrast, neurons with high spontaneous rates and low thresholds typically oppose smaller AZs with weaker, but more hyperpolarized, operating $\mathrm{Ca}^{2+}$ influx, located on the lateral (pillar) sides of IHCs (Winter et al., 1990; Ohlemiller et al., 1991; Merchan-Perez and Liberman, 1996; Taberner and Liberman, 2005; Meyer et al., 2009; Ohn et al., 2016). Therefore, it was hypothesized that the IHC decomposes sound intensity information into these different neural channels via diversifying the operating range of the $\mathrm{Ca}^{2+}$ influx among the AZs (Ohn et al., 2016; Pangrsic et al., 2018; Jean et al., 2019). However, the mechanisms that specify differences in presynaptic AZs have not been determined and the proposed link to the physiological properties of individual SGNs requires experimental confirmation. If postsynaptic SGNs are able to influence the physiology of presynaptic AZs, then this would provide exciting insights regarding the mechanisms that establish intensity coding over the wide audible range within the auditory system.

Recently, single-cell RNA sequencing (RNAseq) has identified at least three categories of type I SGNs based on transcriptional expression profiles (Petitpré et al., 2018; Shrestha et al., 2018; Sun et al., 2018). Although the molecular profiles for each of these groups are distinct, there is currently no data to confirm the postulated correspondence to any of the three functionally defined SGN groups. Pou4f1, a member of the POU (Pit-Oct-Unc) family of transcription factors, was shown to be more strongly expressed in a single class of type I SGNs in each study. POU transcription factors are largely neurospecific molecules that are important for neurogenesis, differentiation, and survival (Tantin, 2013; Malik et al., 2018). The three members of the POU4F subfamily are expressed in distinct but overlapping populations of neuronal and somatic cells in developing and adult tissues (Jehn et al., 1994; Sajgo et al., 2017). Previous studies have demonstrated that Pou4f1 is broadly expressed in all SGNs beginning as early as the onset of neurogenesis at embryonic day 10 (E10)

Foundation via the Leibniz program (Grant M0 896-5), and the Center for Nanoscale Microscopy and Molecular Physiology of the Brain (Grant EXC171/FZT103 to T.M.). We thank Tudor Badea (National Eye Institute) and Lisa Goodrich (Harvard Medical School) for providing transgenic mice; the veterinarians and staff in the Shared Animal Facility in the Porter Neuroscience Center for providing outstanding animal care; Gerhard Hoch for developing Matlab programs for image analysis; Sandra Gerke and Christiane Senger for expert technical assistance; Alejandro Anaya-Rocha, Madison Mehlferber, and YeonSoo Kim for technical assistance with RNAscope and single-cell RNAseq analysis; and Doris Wu and Thomas Coate for reading an earlier version of this manuscript. The gEAR portal, established and maintained by Ronna Hertzano, University of Maryland, was used to generate some of the RNAseq images.

The authors declare no competing financial interests.

*H.E.S. and P.J. contributed equally to this work.

${ }^{\dagger}$ T.M. and M.W.K. are co-senior authors.

Correspondence should be addressed to Matthew W. Kelley at kelleymt@nidcd.nih.gov or Tobias Moser at tmoser@gwdg.de.

https://doi.org/10.1523/JNEUROSCI.2728-18.2019

Copyright $\odot 2019$ the authors
(Huang et al., 2001; Deng et al., 2014). Germline deletion of Pou4f1 leads to significant pathfinding defects within the entire SGN population and, ultimately, to a loss of $\sim 30 \%$ of all SGNs (Huang et al., 2001). However, transcriptomic and immunological analyses indicate that expression of Pou4f1 begins to be down-regulated in some SGNs as early at E16, with only a limited population of SGNs maintaining expression of Pou4f1 beyond birth (Deng et al., 2014). Given the role of Pou4f1 in cell fate specification, we sought to characterize those SGNs that maintain expression of Pou4f1. Moreover, using morphological and functional analysis of AZ properties in the IHCs of mice with conditional deletion of Pou4f1, we examined the hypothesis that Pou $4 \mathrm{fl}^{+}$SGNs provide an instructive, trans-synaptic influence on their presynaptic inputs.

\section{Materials and Methods}

Animals

All mice were maintained according to guidelines established by the joint Nation Institute on Neurological Disorders and Stroke/National Institute on Deafness and Other Communication Disorders institutional animal care and use committee at the National Institutes of Health. Handling of mice in Göttingen complied with national animal care guidelines. Mice of either sex were used for all experiments. Most mice were maintained as mixed strains of predominately CD1 and C57-B6 background. Both the Pou4f ${ }^{\text {flox }}$ and Pou $4 \mathrm{fl}^{-1-}$ mice were obtained from Tudor Badea at the National Eye Institute (Badea et al., 2009a,b; Xiang et al., 1996), Ngn1 ${ }^{\text {creErt2 }}$ mice were obtained from Lisa Goodrich at Harvard Medical School (Koundakjian et al., 2007), and Pou4f1 ${ }^{\text {creErt2 }}$ mice were provided by Jian Zhong at Weill Cornell Medical College (O’Donovan et al., 2014). Atoh1 ${ }^{\text {cre }}, R 26 R^{\text {tdTomato }}$, and $M a p t^{\mathrm{tm} 1(\mathrm{EGFP})} / J$ lines were obtained from The Jackson Laboratory. Plugs were assumed to occur at midnight, so midday on the day that a plug was observed was considered to be E0.5. Embryos were collected in PBS from euthanized pregnant dams. Postnatal pups were euthanized with $\mathrm{CO}_{2}$ followed by decapitation. Cochleae were collected and fixed in $4 \%$ paraformaldehyde in PBS for $1 \mathrm{~h}$ at room temperature. Tissues requiring a short fixation were exposed to 4\% PFA in PBS for $20 \mathrm{~min}$. P14 cochlea were decalcified in 10\% EDTA, pH 7.4, in PBS for 48 h. For cryosectioning, cochleae were cryoprotected through a gradient of sucrose $(5 \%$, $15 \%, 20 \%, 25 \%$, and $30 \%$ ) and embedded and frozen in OCT embedding medium (Fisher Scientific). Sections 10 to $14 \mu \mathrm{m}$ thick were collected onto slides and allowed to dry at room temperature overnight before being frozen at $-80^{\circ} \mathrm{C}$.

\section{Tamoxifen regime}

Pregnant dams were given a combined single dose of 0.2-0.5 g/40 g of body weight tamoxifen (T5648; Sigma-Aldrich) and $2 \mathrm{~g}$ of progesterone diluted in sunflower and flax oil by oral gavage on $1 \mathrm{~d}$ between E9.5 and E12.5.

\section{Immunolabeling of fixed tissue}

Both whole cochleae and cryosectioned tissue were permeabilized and blocked in $0.05 \%$ Triton X-100 in PBS with $10 \%$ normal serum (goat or horse, depending on the species the secondary antibody was raised in) for $1 \mathrm{~h}$ at room temperature. If the primary antibody was raised in mouse, then the blocking solution would also include $0.5 \%$ Unconjugated AffiniPure FAB fragment goat Anti-mouse IgG $(\mathrm{H}+\mathrm{L})$ (Jackson ImmunoResearch Labs). Cochleae were washed 3 times for 5 min with PBS. Tissue was then incubated with the appropriate concentration of primary antibody in $0.05 \%$ Triton X-100 in PBS overnight at $4^{\circ} \mathrm{C}$. Tissue was then washed 3 times for 10 min to ensure primary antibody was thoroughly removed. Species-appropriate Alexa Fluor-conjugated secondary antibodies (1:1000) were then incubated with the tissue for $1 \mathrm{~h}$ at room temperature. When appropriate, DAPI (300 nm) was applied to whole cochleae for $5 \mathrm{~min}$ at room temperature. Tissue was washed 3 times for 10 min each. Whole cochlear tissue was divided into basal and apical pieces and then mounted in Fluoromount-G (Southern Biotechnology). Sec- 
Table 1. Passive electrical properties of patch-clamp recording experiments

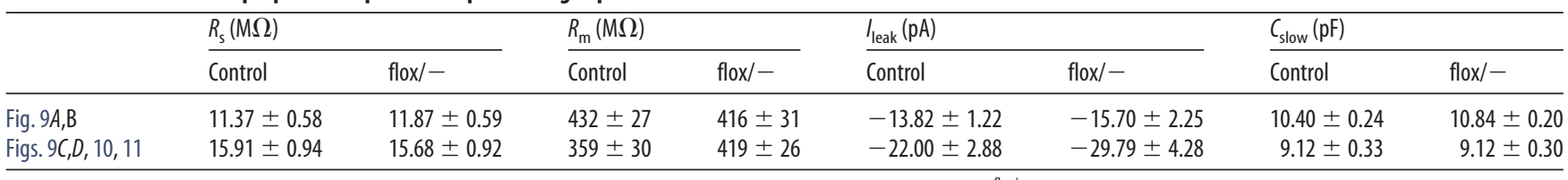

Shown is the mean \pm SEM of the passive electrical properties across all ruptured patch-clamp recording experiments in control and Atoh $1^{\text {cre }}$;Pou4f ${ }^{\text {flox } /-}$ conditions. $_{\text {. }}$

tioned tissue was mounted in DAPI Fluoromount-G or Fluoromount-G (Southern Biotechnology).

For sectioned tissue stained using the anti-Brn3a (Pou4f1) antibody, antigen retrieval was performed before immunolabeling. Briefly, slides were placed on a platform above the boiling water in a commercially purchased rice cooker and covered with sodium citrate buffer $(10 \mathrm{~mm}$ sodium citrate, $0.05 \%$ Tween, $\mathrm{pH} 6.0$ ). Slides were steamed in the sodium citrate buffer for $10 \mathrm{~min}$ and then allowed to cool for $10 \mathrm{~min}$. Slides were then washed in PBS three times and immunolabeling was performed as above.

The following primary antibodies were used: anti-Pou4f1 (Millipore; MAB1585), anti-Myosin7a (Proteus Biosciences; 25-6790), anti-CtBP2 (Santa Cruz Biotechnology; SC5967), anti-beta-Tubulin 3 (Tuj1; SigmaAldrich; T2200), anti-Neurofilament Heavy (Aves Labs; NFH), and antitdTomato (Kerafast; 16D7).

\section{RNAscope}

Cochlear tissue was dissected, fixed, embedded, and cryosectioned as described above. A probe against mouse Pou $4 \mathrm{fl}$ was ordered from Advanced Cell Diagnostics (ACD). Cryosections were hybridized with the Pou 4 f1 probe following the protocol provided by ACD. Sections were counterstained with DAPI and imaged on a Zeiss LSM780.

\section{Single-cell RNAseq}

Cochleae were dissected from P1 Mapt ${ }^{\mathrm{EGFP}}$ pups. The cochlear epithelium was removed, leaving the surrounding mesenchyme and spiral ganglia intact. Spiral ganglia from an entire litter were pooled and then dissociated in $0.05 \%$ Trypsin-EDTA for $14-17 \mathrm{~min}$ at $37^{\circ} \mathrm{C}$ with $2-3$ triturations using a P200. Following Trypsin inactivation with FBS, dissociated cells were passed through a $40 \mu \mathrm{m}$ nylon filter and then centrifuged at $1400 \mathrm{rpm}$ for $5 \mathrm{~min}$. Dissociated cells were then dissociated to a final concentration of $1-2 \times 10^{6}$ cells $/ \mathrm{ml}$.

Single $\mathrm{EGFP}^{+}$-neurons were isolated into single wells of a 96-well plate on a Sony SH800 FACS machine. Neurons were then lysed and reverse transcription and amplification were performed as described by Picelli et al. (2014). Tagmentation and library preparation of the resulting single-cell cDNA was performed following the protocol described in Fluidigm Protocol (PN 100-6260). RNAseq and data analysis were performed as described by Burns et al. (2015). Further details, including the complete dataset, will be provided in a subsequent publication.

\section{Auditory testing}

Auditory brainstem responses (ABRs) were obtained as described previously (Morozko et al., 2015) using a Tucker-Davis system at 8, 16, 32, and $40 \mathrm{kHz}$. Animals were tested at 1,3, and 5 months of age.

Patch-clamp and live confocal $\mathrm{Ca}^{2+}$ imaging

The apical 2/3 turns of organs of Corti from P21-P28 mice were freshly dissected in HEPES Hank's solution containing the following (in $\mathrm{mM}$ ): $5.36 \mathrm{KCl}, 141.7 \mathrm{NaCl}, 10 \mathrm{HEPES}, 0.5 \mathrm{MgSO}_{4-} 7 \mathrm{H}_{2} \mathrm{O}, 1 \mathrm{MgCl}_{2}-6 \mathrm{H}_{2} \mathrm{O}, 1$ $\mathrm{mg} / \mathrm{ml} \mathrm{D}$-glucose, and $0.5 \mathrm{mg} / \mathrm{ml} \mathrm{L}$-glutamine, $\mathrm{pH} 7.2, \sim 300 \mathrm{mOsm}$. The native morphologies and positions of the IHCs within the organ of Corti were maintained as much as possible by exposing the modiolar face of the IHC and carefully removing the surrounding supporting cells with a suction pipette. All experiments were conducted at room temperature $\left(20-25^{\circ} \mathrm{C}\right)$. The patch pipette solution contained the following (in $\mathrm{mM}$ ): 111 Cs-glutamate, $1 \mathrm{MgCl}_{2}, 1 \mathrm{CaCl}_{2}, 10$ EGTA, 13 TEA-Cl, 20 HEPES, 4 Mg-ATP, 0.3 Na-GTP and 1 L-glutathione, pH 7.3, 290 mOsm. To visualize the $\mathrm{Ca}^{2+}$ hotspots and the ribbons, the $\mathrm{Ca}^{2+}$ indicator Fluo$4 \mathrm{FF}$ penta- $\mathrm{K}^{+}$salt $(0.8 \mathrm{~mm}$; Life Technologies) and the TAMRAconjugated CtBP2/RIBEYE-binding dimer peptide (10 $\mu \mathrm{M}$; Biosynthan) were added to the intracellular solution just before the experiment. The extracellular solution contained the following (in $\mathrm{mM}$ ): $2.8 \mathrm{KCl}, 102$ $\mathrm{NaCl}, 10 \mathrm{HEPES}, 1 \mathrm{CsCl}_{2}, 1 \mathrm{MgCl}_{2}, 5 \mathrm{CaCl}_{2}, 35 \mathrm{TEA}-\mathrm{Cl}$, and $2 \mathrm{mg} / \mathrm{ml}$ D-glucose, $\mathrm{pH} 7.2, \sim 300 \mathrm{mOsm}$.

An EPC-10 amplifier controlled by Patchmaster (HEKA Elektronik) was used for the acquisition. IHCs were held at $-87 \mathrm{mV}$. All voltages were corrected offline for liquid junction potential $(-17 \mathrm{mV})$ and voltage drops across the series resistance $\left(R_{\mathrm{s}}\right)$. Recordings were discarded when exceeding a leak current of $-50 \mathrm{pA}$ at $-87 \mathrm{mV}$, an $R_{\mathrm{s}}$ of $15 \mathrm{M} \Omega$ within 4 min after break-in, or a $\mathrm{Ca}^{2+}$ current rundown of $25 \%$. The passive electrical properties of the patch-clamp recordings are detailed in Table $1 . \mathrm{Ca}^{2+}$ imaging was performed with a spinning-disk confocal scanner (CSU22; Yokogawa) mounted on an upright microscope (Axio Examiner; Zeiss) with $63 \times, 1.0$ numerical aperture objective (W PlanApochromat; Zeiss). Images were acquired by a scientific CMOS camera (Neo; Andor). $\mathrm{Ca}^{2+}$ indicator F4FF and TAMRA-conjugated peptide were excited by diode-pumped solid-state lasers with 491 and $561 \mathrm{~nm}$ wavelength, respectively (Cobolt). The spinning disk was set to $2000 \mathrm{rpm}$ to synchronize with the $100 \mathrm{~Hz}$ acquisition rate of the camera.

Using a piezo positioner for the objective (Piezosystem), a scan of the entire cell was performed 4 min after breaking into the cell, taking sections each $0.5 \mu \mathrm{m}$ at an exposure time of $0.5 \mathrm{~s}$ in the red (TAMRA peptide) channel from the bottom to the top of the cell. To study the voltage dependence of $\mathrm{Ca}^{2+}$ indicator fluorescence increments at the synapses, the confocal scans were acquired every $0.5 \mu \mathrm{m}$ from the bottom-most to the top-most ribbon. $\mathrm{Ca}^{2+}$ currents were evoked by applying a voltage-ramp stimulus from -87 to $+63 \mathrm{mV}$ during $150 \mathrm{~ms}$ $(1 \mathrm{mV} / \mathrm{ms})$ in each focal plane. Simultaneously, fluorescence measurements were made in the green channel (Fluo-4FF) with a frame rate of $100 \mathrm{~Hz}$. To overcome the limitations of the frame rate and to increase the voltage resolution of the fluorescent signal acquired, the voltageramp protocol was applied twice, once shifted by $5 \mathrm{~ms}$ such that for any given frame, during the second ramp, the voltage was shifted by 5 $\mathrm{mV}$ compared with the first stimulus. Alternating planes were acquired to avoid photobleaching encountered with the consecutive plane acquisitions.

\section{Data analysis}

IHC live $\mathrm{Ca}^{2+}$ imaging and patch clamp data. The data were analyzed using custom programs in Igor Pro 6.3 (Wavemetrics). For analysis of $\mathrm{I} / \mathrm{V}$ curves, the evoked $\mathrm{Ca}^{2+}$ currents were averaged from 5 to $10 \mathrm{~ms}$ after the start of the depolarization. $\Delta F$ images were created by subtracting the fluorescence intensities inside the cell at resting state $\left(F_{0}\right.$, average of 10 frames) from the ones at the depolarized state (average of six frames during voltage ramp protocol). $\Delta F$ for each hotspot was calculated as the average of a 9 pixel square placed in the region exhibiting the greatest intensity increase within the fluorescent hotspot. The fluorescence-voltage relationship (FV) was sorted by the corresponding voltage of each fluorescence intensity value. Maximal $\Delta F\left(\Delta F_{\max }\right)$ was the average of five $\Delta F$ values obtained during the voltage-ramp protocol (at the peak of $\mathrm{Ca}^{2+}$ influx). Only fluorescent increments presenting a $\Delta F_{\max }$ greater than the average of the fluorescence intensity plus 2 SDs at rest were defined as synaptic $\mathrm{Ca}^{2+}$ signals and considered for further analysis. Due to their variance, analysis of their voltage dependence was performed on fits to the raw FV traces using the following function:

$$
F(V)=F_{0}+\frac{f_{v} \cdot\left(V_{r}-V\right)}{1+e^{\frac{\left(V_{h}-V\right)}{k}}}
$$


where $V$ is the voltage command. The fitting parameters were determined by Igor Pro automatically and their initial guess resulted from the estimations of $F_{0}$, the signal at rest, $V_{\mathrm{h}}$ for the voltage value of halfmaximal activation, and $k$ for the voltage sensitivity obtained from a sigmoid fitting. The slope factor $f_{\mathrm{v}}$ was obtained by linear fitting of the FV trace in the range of $3-23 \mathrm{mV}$, where the decrease of fluorescence at positive voltages results from the declining driving force despite full activation of the $\mathrm{Ca}^{2+}$ channels. The resulting fitting trace was forced to reach the reversal potential $V_{\mathrm{r}}$, obtained from the corresponding wholecell $\mathrm{Ca}^{2+}$ currents. The FV fit was then divided by the $f_{\mathrm{v}}$ line extended to all the corresponding voltages to estimate the assumed fluorescence intensity of every voltage in the full activation condition, giving the fractional activation curves. The fractional activation curves were then fitted by the Boltzmann function to obtain the voltage for half activation $\left(V_{\mathrm{h}}\right)$ and slope-factor $(k)$.

Live TAMRA peptide imaging and $3 D$ reconstruction of IHC. The fluorescence intensity of the synaptic ribbon (visualized with the TAMRAconjugated CtBP2/RIBEYE-binding dimer peptide) was estimated by measuring the ratio of the strongest fluorescence pixel intensity to that of the pixels nearby the ribbon ( $8-9$ pixels away from the ribbon inside the cell) $\left(F_{\text {ribbon }} / F_{\text {nearby }}\right)$. To combine live-imaging data from multiple cells, we reconstructed the morphology of individual IHCs and the positions of their synapses based on the fluorescence of the TAMRA-conjugated RIBEYE-binding peptide and then transformed the Cartesian coordinates into cell-aligned cylindrical coordinates (for more details, see Ohn et al., 2016). In brief, for each cell, we identified the plane of symmetry orthogonal to the tonotopic axis. Then, we sectioned the IHC orthogonally to a straight line fitting the pillar edge of the cell in the plane of symmetry. We calculated the center of mass for each section and connected those of the bottom-most and of the largest section to define the central axis for our cylindrical coordinate system. We projected the AZ coordinates of multiple cells along their central axis for the polar charts, with the four sides annotated as modiolar or pillar (facing toward or away from the ganglion) and apical or basal (toward the cochlear tonotopic apex or base).

Analysis of confocal immunofluorescence imaging data. To analyze the immunofluorescence intensity and position of ribbons in confocal images of fixed and immunolabeled whole-mount organs of Corti, a customized algorithm was developed as a program in MATLAB software and used as a plug-in in Imaris software. The locations of the ribbons were defined as the centers of mass of CtBP2-immunofluorescent spots by fitting Gaussian functions in three dimensions. The spots were selected by a subjective criterion of the quality of the fitting. Immunofluorescence intensities were measured as the sum of the voxel values within a defined region (three voxels in $X$ and $Y$ and two in $Z$ ) with the center of mass of the spot as origin. The cytosolic staining allowed us to assign each ribbon to an IHC. After marking the center of each IHC nucleus, a vector passing by this point and defining the central axis of the cylindrical model of the cell was placed by being adjusted to the relative orientation of each IHC cell in the XY and YZ axis. The Cartesian coordinates of the ribbons were transformed to cell-centric cylindrical coordinates to adjust differences in cellular orientation relative to the XYZ axes of the microscope. Intensities of CtBP2 puncta as a function of their positions could be analyzed for multiple cells by overlaying their central axes with alignment to the center of each nucleus (for more details, see Ohn et al., 2016).

\section{Statistical analysis}

The data were analyzed using MATLAB (The MathWorks), Excel (Microsoft), and Igor Pro 6 (Wavemetrics). Averages were expressed as mean \pm SEM. For every dataset, the SD, number of replicates $(n)$, and number of animals $(N)$ are indicated. To compare two samples, datasets were tested for normal distribution (Jarque-Bera test) and equality of variances ( $F$ test) followed by two-tailed unpaired Student's $t$ test or, when data were not normally distributed and/or variance was unequal between samples, the unpaired two-tailed Mann-Whitney-Wilcoxon test was used. The nonsignificant difference between samples is reported as "n.s."; significant differences are reported as ${ }^{\star} p<0.05,{ }^{\star *} p<0.01$, ${ }^{* * *} p<0.001$, and ${ }^{* * *} p<0.0001$.

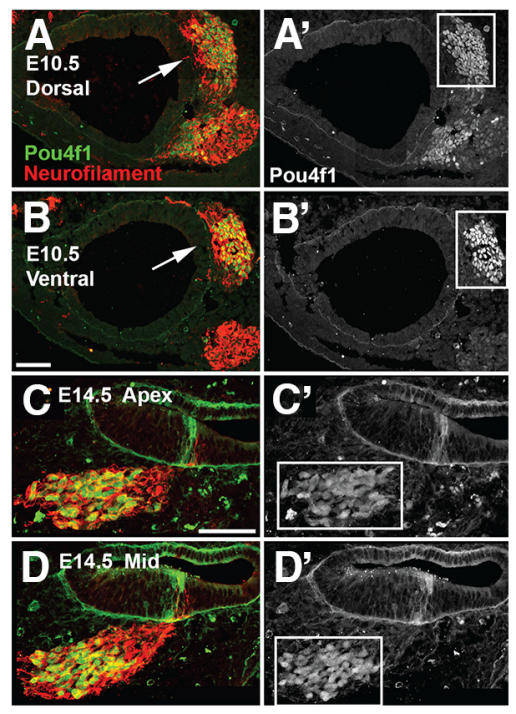

Figure 1. Pou4f1 is broadly expressed in developing cochleovestibular ganglia and SGNs at early time points. $\boldsymbol{A}, \boldsymbol{B}$, Expression of Pou4f1 at E10.5. Cross-sections through the dorsal $(\boldsymbol{A})$ and ventral $(\boldsymbol{B})$ portions of the otocyst indicate that Pou4f1 (green) is initially expressed in most neurons (neurofilament in red) within the CVG (arrows in $\boldsymbol{A}, \boldsymbol{B}$, boxed in $\boldsymbol{A}^{\prime}, \boldsymbol{B}^{\prime}$ ). $\boldsymbol{C}-\boldsymbol{D}$, Midmodiolar sections through the cochlea at E14.5. Pou4f1 is still broadly expressed in the cell bodies within the developing $S G . \boldsymbol{C}^{\prime}, \boldsymbol{D}^{\prime}$, boxed region indicates spiral ganglion in grayscale. Panels labeled as in $\boldsymbol{A}$. Scale bars in $\boldsymbol{B}$ (same as in $\boldsymbol{A}$ ) and $\boldsymbol{C}$ (same as in $\boldsymbol{D}$ ), $100 \mu \mathrm{m}$.

\section{Results}

\section{Expression of POU4F1 is restricted to a subset of SGNs beginning at E16}

Previous studies have suggested that nearly $90 \%$ of all SGNs are positive for Pou4f1 at P0 (Huang et al., 2001). To determine whether a similar pattern of expression is true at the protein level, anti-POU4F1 immunolabeling was performed on sectioned inner ears from E10.5, E14.5, E16.5, P0, and P14. As previously reported, at E10.5 and E14.5, all, or nearly all, neurons within the cochleovestibular ganglion and developing vestibular and spiral ganglia were positive for POU4F1 (Fig. 1). In addition, POU4F1 was also expressed by a few neurons in the closely associated facial ganglion (Fig. 1).

In contrast, at E16.5, there was a notable reduction in the number of POU4F1 ${ }^{+}$neurons in the base of the cochlea $(38 \pm$ $12 \%$ of total, $n=3$ ), whereas all SGNs in the apex were still positive for POU4F1 ( $100 \pm 0 \%, n=3$ ) (Fig. 2). The number of POU4F ${ }^{+}$neurons in the middle turn was intermediate $(51 \pm$ $12 \%, n=3$ ) between basal and apical values, suggesting a development downregulation of POU4F1. At P1, the number of POU4F1 ${ }^{+}$SGNs was decreased somewhat in the base, dropping to $31 \pm 4 \%(n=8)$. Decreases to similar numbers were observed in the middle turn $(30 \pm 1.2 \%, n=8)$ and in the apex, which decreased to $35 \pm 3 \%(n=8)$. Finally, at P14, around the onset of hearing, POU4F1 expression was only present in a total of $28 \pm$ $9 \%(n=5)$ of SGNs; however, a slight gradient still appeared to persist, with more POU4F1 ${ }^{+}$cells located in the apical turn. These results are consistent with single-cell RNAseq analyses suggesting that $\sim 1 / 3$ of SGNs maintain expression of Pou $4 \mathrm{fl}$ at adult stages (Petitpré et al., 2018; Shrestha et al., 2018; Sun et al., 2018).

\section{Peripheral axons from POU4F1 ${ }^{+}$SGNs terminate on the modiolar side of IHCs}

To determine whether POU4F1 ${ }^{+}$SGNs share any phenotypic characteristics, transgenic Pou $4 f^{\text {creErt2 }}$ mice (O'Donovan et al., 2014 ) were combined with either $R 26 R^{\text {zsgreen }}$ or $R 26 R^{\text {tdTomato }}$ 

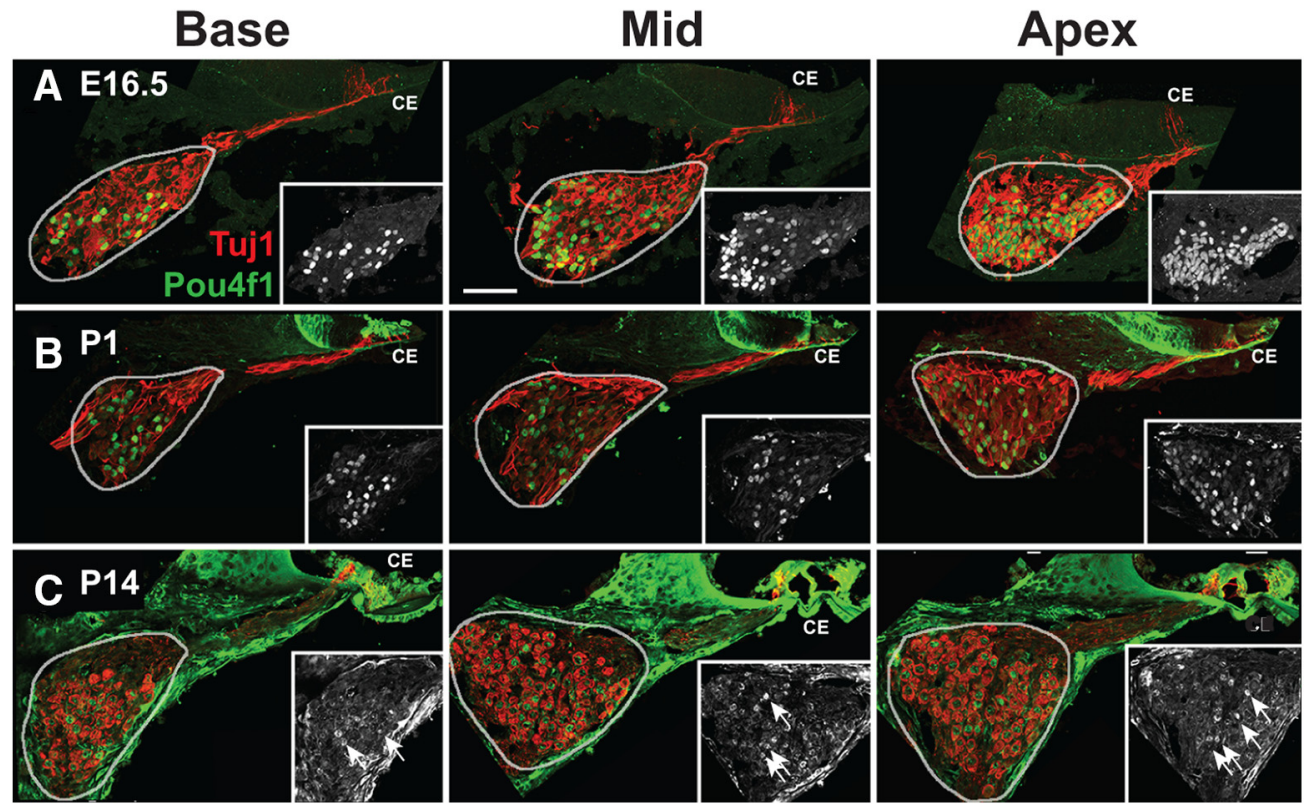

Figure 2. Expression of Pou4f1 changes with development. $\boldsymbol{A}-\boldsymbol{C}$, Mid-modiolar cross-sections through the cochlear duct at the indicated time points and cochlear positions. SGNs are labeled with Tuj1 (red) and Pou4f1 (green). For each panel, the SG is circled. Insets show expression of Pou4f1 alone in the SG. Compared with E14.5, the number of SGNs that express Pou4f1 has decreased by E16.5, although a clear basal to apical gradient is present with more Pou4f1 ${ }^{+}$SGNs in the apex. The number of Pou4f1 ${ }^{+}$SGNs continues to decrease at both P1 and P14, but $32 \%$ of SGNs remain positive for Pou4f1 at P14 (arrows). CE, Cochlear epithelium. Scale bar in $\boldsymbol{B}$ (same for all other panels), $100 \mu \mathrm{m}$.

reporter mice. Induction of creErt2 activity was achieved by daily subcutaneous injections of tamoxifen for 3-7 d beginning on P5 (see Materials and Methods). Results indicated reporter expression in $>60 \%$ of SGNs, both type I and type II (data not shown). This result was surprising given the consistent labeling of $\sim 32 \%$ of SGNs using antibodies at the same age and the comparable results obtained by single cell RNAseq (Petitpré et al., 2018; Shrestha et al., 2018; Sun et al., 2018). Specificity of the antibody used has been confirmed in several previous studies (Blanchard et al., 2015; Hua et al., 2015) and our results indicate a complete loss of antibody labeling in SGNs from Pouf41 mutant mice (see below). To confirm that SGNs expressing the reporter were also positive for POU4F1, induced cochleae were sectioned and counterstained for POU4F1 (Fig. 3). A relatively limited number of tdTomato ${ }^{+}$neurons were also positive for nuclear POU4F1 (Fig. 3 ). To determine whether the mismatch between reporter activity and POU4F1 expression could be the result of a downregulation of POU4F1 between the time of induction and fixation, P0 embryos were induced for 3 consecutive days and then fixed on the fourth day. Tissue sections indicated a similar mismatch between reporter activity and antibody labeling (data not shown). A specific explanation for this discrepancy is unclear but may be related to the method by which the Pou $4 f 1^{\text {creErt2 }}$ line was created. The creErt2 sequence was linked to an $11 \mathrm{~kb}$ Pou $4 f 1$ upstream promoter and then delivered by pronuclear injection (O'Donovan et al., 2014). Subsequent analysis of reporter expression in the spinal cord appeared to correspond with the known expression pattern of POU4F1, but similar examination of reporter expression in the SGN was not determined. Therefore, it is possible that the $11 \mathrm{~kb}$ upstream regulatory sequence lacks regulatory elements that are crucial for accurate SGN expression.

Based on the results described above, we decided to examine the phenotype of Pou $4 \mathrm{fl}^{+}$SGNs by combining antibody labeling with genetic sparse labeling of SGNs using a $\mathrm{Ngn}^{\mathrm{CreErt}}$; $R 26 R^{\text {TdTomato }}$ mouse line (Koundakjian et al., 2007; Coate et al.,
2015). The $N g n 1^{\text {CreErt2 }} ; R 26 R^{\text {TdTomato }}$ labeling strategy results in expression of tdTomato throughout the entire length of individual SGNs. Cochleae were dissected at P3, immunolabeled with anti-POU4F1 antibodies, and then prepared as whole mounts. SGN cell bodies that were positive for POU4F1 and tdTomato were identified and the peripheral projections of those cells were traced to their targets in the organ of Corti (Fig. 4). SGNs that were strongly positive for POU4F1 and tdTomato were found to terminate preferentially on the modiolar side of IHCs (Fig. 4). This distribution significantly differed from the distribution of all sparsely labeled fibers, only half of which terminated on the modiolar sides of IHCs (Fig. 4). The modiolar localization of synaptic contacts is consistent with the category of type 1 SGNs that have been described as having a low spontaneous firing rate in the cat (Liberman, 1982; Merchan-Perez and Liberman, 1996). It should be noted that, whereas the peripheral axons from nearly all POU4F ${ }^{+}$SGNs terminate on the modiolar sides of IHCs, it is not the case that every modiolar synapse was formed with a cell that was positive for POU4F1. This suggests that POU4F1 defines a subgroup within the larger population of low-spontaneous-rate fibers.

\section{Tissue-specific deletion of Pou4f1 using ectopic} Atoh $1^{\text {cre }}$ expression

To determine the role of Pou4f1 in the subset of lowspontaneous-rate fibers, we wanted to delay deletion of the gene until after the early period of broad expression in nearly all SGNs (Huang et al., 2001). Initial attempts using $N g n 1^{\text {creErt2 }}$ yielded either a recapitulation of the phenotype observed in germlinedeleted animals, including death of the animal on P0, or no deletion of Pou4f1, depending on the dose of tamoxifen used. As discussed above, our results indicated that recombination using the Pou $f 1^{\text {creErt2 }}$ line did not reflect the endogenous pattern of Pou4f1 expression and, as a result, this line could not be used to reliably delete Pou 4 f1. Therefore, we decided to take advantage of 

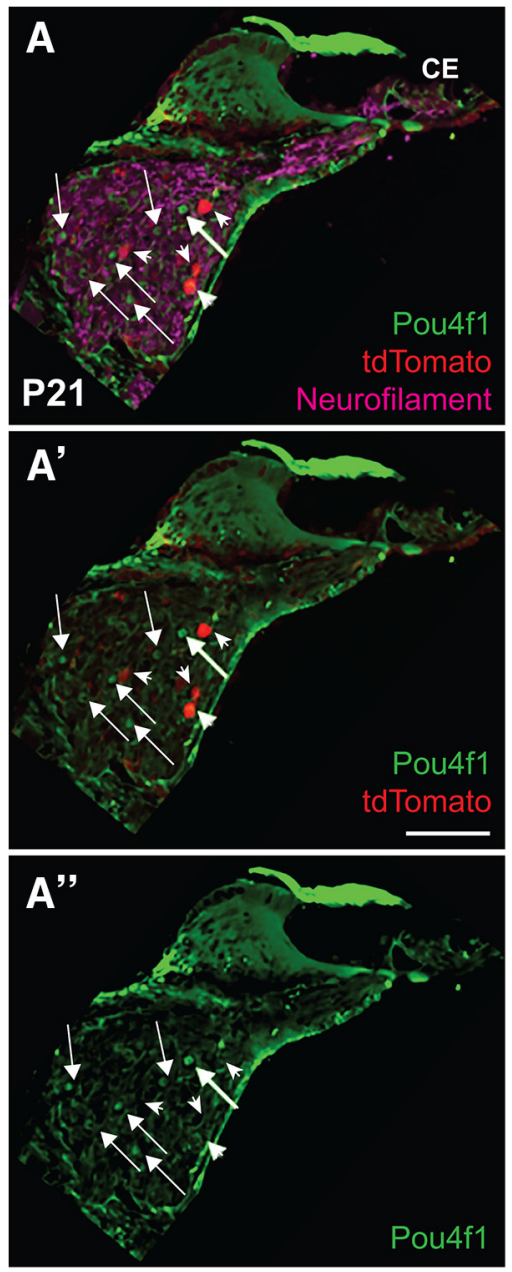

Figure 3. Pou4f1 ${ }^{\text {creErt2 }}$-mediated recombination occurs in cells that are not positive for Pou4f1, $A$, Induction of Pou4f1 ${ }^{\text {creert2 }}$ at P14 labeled SGNs that were not positive for Pou4f1 protein after $7 \mathrm{~d}$ (P21). Arrows indicate Pou4f1 ${ }^{+}$SGNs and arrowheads indicate SGNs that express tdTomato as a result of recombination. There is limited overlap between the two sets of SGNs. $\boldsymbol{A}^{\prime}$, Same image as in $\boldsymbol{A}$, but with neurofilament labeling removed to aid in visualization of tdTomato and Pou4f1 labeling. $\boldsymbol{A}^{\prime \prime}$, Same image as in $\boldsymbol{A}$, but only showing Pou4f1 labeling. Arrows and arrowheads in $\boldsymbol{A}^{\prime}$ and $\boldsymbol{A}^{\prime \prime}$ are the same as in $\boldsymbol{A}$. CE, Cochlear epithelium Scale bar, $50 \mu \mathrm{m}$.

the known ectopic cre expression in the SG in one of the early Atoh $1^{\text {cre }}$ lines (Matei et al., 2005). This line was generated by placing the Atoh1 3' enhancer upstream of cre (Lumpkin et al., 2003). The resulting transgenic mice show ectopic expression in a number of tissues, including the SG, that are negative for Atoh1/ ATOH1 based on in situ hybridization, immunolabeling, or RNA-seq profiling. Initial transgene expression in the SG begins on E14.5 (data not shown). Atoh $1^{\text {cre }}$ mice were crossed with Pou4f1 $1^{\text {flox/ - }}$ mice (Xiang et al., 1996; Badea et al., 2009a,b) to yield Atoh $1^{\text {cre }}$;Pou $4 \mathrm{f} 1^{\text {floxl- }}$ mice. Analysis of the SG in Atoh $1^{\text {cre }}$; Pou $4 \mathrm{fl}^{\text {flox/- }}$ mice at E17.5 indicated a nearly complete absence of POU4F1 expression compared with controls (Fig. 5). By P1, virtually no expression of POU4F1 was observed in the nuclei of Atoh $1^{\text {cre }} ;$ Pou $4 \mathrm{fl}^{\text {flox/- }}$ mice.

Pou4f1 is not expressed in hair cells or supporting cells. Although use of the Atoh $1^{\text {cre }}$ line was effective in deleting Pou $4 \mathrm{fl}$ in the spiral ganglion, the expression of Atoh $1^{\text {cre }}$ in hair cells meant that Pou $f 1$ was deleted in this cell population as well.
Previous results had reported no expression of Pou4f1/POU4F1 in hair cells or the organ of Corti (Huang et al., 2001; Badea et al., 2012; Deng et al., 2014); however, we wanted to confirm the absence of Pou4f1/POU4F1 expression in hair cells. As a first step, we repeated immunolocalization of POU4F1 in cross-sections of the cochlear duct at five different time points between E16 and P7 (Fig. 6A). No expression of POU4F1 was observed in either hair cells or supporting cells between E16 and P5 (Fig. 6A). However, whereas hair cells were negative at P7, some possible labeling was observed in supporting cells at this time point. Our previous results had suggested an increase in nonspecific labeling with the POU4F1 antibody beginning after the first postnatal week (Fig. 2). Therefore, to discriminate between these possibilities, we performed mRNA in situ hybridization of cochlear sections using RNAscope (see Materials and Methods) at P1 and P7. Fluorescent puncta indicative of Pou $4 \mathrm{fl} \mathrm{mRNA}$ molecules were present in the nuclei of SGNs at both time points (Fig. $6 B, C$ ). In contrast, no puncta were observed in hair cells or supporting cells at either time point. Next, we used the gEAR portal to query four recently published RNAseq datasets (Cai et al., 2015; Elkon et al., 2015; Li et al., 2018; Wiwatpanit et al., 2018) in which hair cells had been isolated at P0 or from adults using fluorescence activated cell sorting (FACS) or visual collection. For comparison, the expression levels of three known hair-cell-specific genes (Pou4f3, Gfi1, $M y o 7 a$ ) were compared with Pou 4 f1. For each dataset, the expression of Pou $4 \mathrm{fl}$ was approximately two orders of magnitude lower by comparison with the known hair cell markers (Fig. 6D). Finally, the expression of Poutf1 was examined in two recently published single-cell RNAseq datasets (Burns et al., 2015; McInturff et al., 2018). To be sure that expression of Pou4f1 can be detected in single cells, we queried a P1 single SGN dataset that we have generated in our laboratory (full dataset to be published in the future). Consistent with the immunolocalization and in situ hybridization data, Pou4f1 is detected in a subset of P0 SGNs (Fig. $6 E)$. In contrast, no expression of Pou $4 f 3$ was observed in SGNs. Examination of expression of Pou $4 \mathrm{fl}$ in single cells isolated from the cochlea at P1 indicates no expression in either hair cells or supporting cells. Similarly, no detection of Pou $4 f 1$ was observed in a dataset of utricular hair cells that includes cells isolated at P1, $\mathrm{P} 12$, and P100. Therefore, although it is not possible to say with $100 \%$ certainty that Pou $4 f 1$ is never expressed at any level in hair cells, the presented results are consistent with previous studies indicating that Pou4f1 is not expressed in hair cells.

\section{Cochlear morphology and ABRs are preserved in Atoh ${ }^{\text {cre; }}$ Pou4f1 ${ }^{\text {flox/- }}$ mice}

Analysis of cochlear whole mounts from P1 Atoh ${ }^{\text {cre }}$;Pou $4 \mathrm{fl}{ }^{\text {flox/- }}$ and control littermates (Atoh $1^{\mathrm{Cre}} ; \mathrm{Pou} 4 \mathrm{f1} 1^{-/+}$) indicated no differences in the length, size, or anatomy of the cochlea (data not shown). Cell counts of SGNs in control or Atoh $1^{\text {cre }}$;Pou $4 \mathrm{fl}{ }^{\text {flox/- }}$ cochleae showed no overall change in cell number (control: $83.8 \pm 5.2$ cells/section, $n=18$, vs Atoh ${ }^{\text {cre }} ;$ Pou $4 f 1^{\text {flox/- }}: 79.1 \pm$ 4.5 cells/section, $n=14 ; p=0.59$, paired $t$ test) or density in the ganglion (control: $43 \pm 6$ cells $/ 100 \mu \mathrm{m}^{3}$ vs Atoh $1^{\text {cre }} ;$ Pou $4 \mathrm{fl}^{\text {flox } /-}$ : $46 \pm 6$ cells $/ 100 \mu \mathrm{m}^{3} ; p=0.52$, paired $t$ test). Consistent with these results, there was no evidence of increased cell death in the SG of Atoh $1^{\text {cre }}$;Pou $4 \mathrm{fl}^{\text {flox/- }}$ animals based on a TUNEL assay at P1 (data not shown). Finally, the innervation of the organ of Corti appeared largely normal with no evidence of the neural overgrowth that was observed in germline Pou4f1 mutants (Huang et al., 2001). These results suggest that both the cell death and neuronal guidance phenotypes seen in the germline 


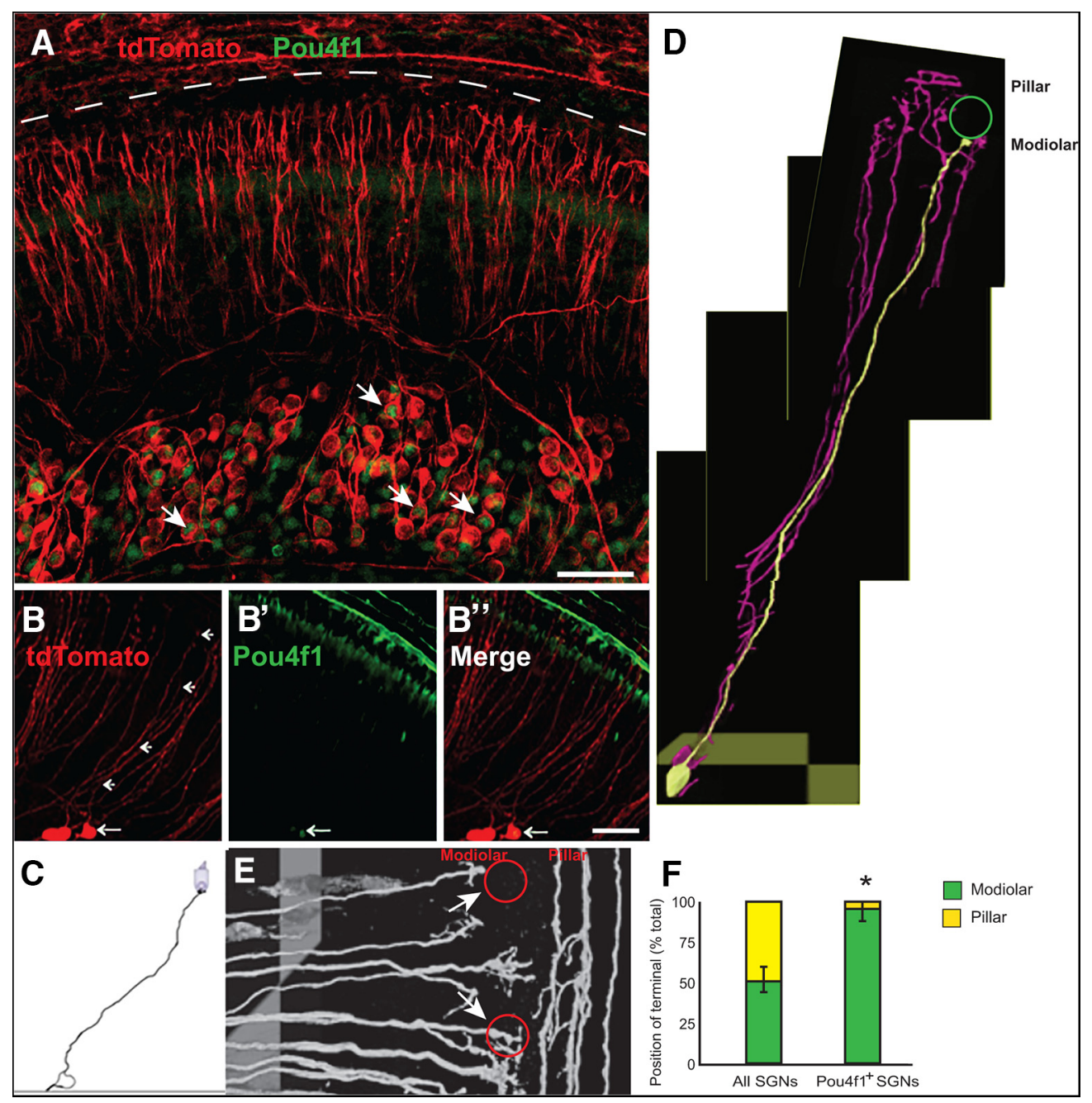

Figure 4. Pou4f1 ${ }^{+}$SGNs terminate on the modiolar sides of IHCS. A, Image of the basal turn from a sparsely labeled Ngn $1^{\text {creert2. }}$; R26R ${ }^{\text {tdtomato }}$ at P7. A subset of the labeled SGN cells (red) are positive for Pou4f1 (green, arrows). $\boldsymbol{B}-\boldsymbol{B}^{\prime \prime}$, Images from another example of SGN sparse labeling. The large arrow at the bottom of the images indicates an SGN cell body that is positive for Pou4f1 (green). Small arrows in $\boldsymbol{B}$ trace the peripheral axon from that labeled cell body. C, Line drawing for the labeled SGN in $\boldsymbol{B}$. D, Composite 3D reconstruction of a single Pou4f1 ${ }^{+}$SGN (yellow), which terminates on the modiolar side of an IHC (indicated by green circle). $E, 3 D$ reconstruction of sparsely labeled SGN terminals. IHC positions are indicated by red circles. Fibers that terminate on the modiolar (top arrow) or the pillar (bottom arrow) side of IHCs can be identified. F, Quantification of terminal locations for all sparsely labeled SGN fibers and for Pou $4 \mathrm{f} 1{ }^{+}$fibers. Slightly more than half $[51 \% ; 95 \%$ confidence interval $(\mathrm{Cl})=43-59 \%, n=154$ terminals $]$ of all labeled fibers terminate on the modiolar side of $\mathrm{IHC}$. In contrast, $96 \%(95 \% \mathrm{Cl}=88-100 \%, n=24$ cells, $p=1.43 \times$ $10^{-6}$, binomial test) of Pou4f1 ${ }^{+}$fibers terminate on the modiolar side of IHCs. Scale bars in $A, B^{\prime \prime}, 50 \mu \mathrm{m} .{ }^{*} p<0.05$.

Pou4f1 $1^{-1-}$ mutants were avoided by using ectopic expression of Atoh $1^{\text {cre }}$ to drive deletion of Pou4f1 beginning at E14.5.

To determine whether deletion of Pou $f 1$ has an overt effect on auditory function, ABRs were recorded for control and Atoh $1^{\text {cre }} ;$ Pou $4 f 1^{\text {flox } /-}$ mice at $\sim 1,3$, and 5 months of age. Both ears were tested for three control and three Atoh $1^{\text {cre }} ; P$ ou $4 \mathrm{fl}^{\text {flox } /-}$ mice at each time point. Results indicated no significant threshold shift at any of the tested frequencies at any of the tested ages (Fig. 7).

\section{Normal pattern of afferent innervation is present in IHCs from Atoh $1^{\text {cre }}$;Pou $4 \mathrm{f1} 1^{\text {flox/- }}$ mice}

To determine whether deletion of Pouffl caused a change in the distribution or morphology of SGN synapses, the position and immunofluorescence intensity (a proxy of "ribbon size"; Wong et al., 2014; Ohn et al., 2016) of the synaptic ribbons in apical hair cells at P14 were analyzed and mapped onto the surfaces of IHCs as described previously (Fig. 8A,B; Ohn et al., 2016). Confocal mapping of synaptic locations using immunostainings against CtBP2 indicated no changes in the proportion of modiolar synapses $\left(366 / 720\right.$ (51\%) for 46 IHCs in Atoh ${ }^{\text {cre }} ;$ Pou $4 \mathrm{fl}^{\text {flox/- }}$ mice vs 350/726 (48\%) synapses for 48 IHCs in control mice. However, a decrease in the mean intensity of CtBP2 immunofluorescence in the synaptic ribbons was observed (pillar side: control: $F_{\mathrm{CtBP} 2}: 1.87 \pm 0.03$ a.u., $\mathrm{SD}=0.54$ a.u. vs $A$ toh $1^{\text {cre }}$; Pou4f1 ${ }^{\text {flox/- }}: F_{\mathrm{CtBP} 2}: 1.60 \pm 0.03$ a.u., $\mathrm{SD}=0.57$ a.u., modiolar side: control: $F_{\mathrm{CtBP} 2}$ : $1.44 \pm 0.03$ a.u., $\mathrm{SD}=0.52$ a.u. vs Atoh $1^{\text {cre }} ;$ Pou $4 \mathrm{fl}^{\text {flox } /-}: F_{\mathrm{CtBP} 2}: 1.18 \pm 0.02$ a.u., $\mathrm{SD}=0.48$ a.u., $p<0.0001$; Fig. $8 \mathrm{~B}, \mathrm{C})$. Interestingly, in contrast to our previous report investigating $\mathrm{P} 14-\mathrm{P} 18 \mathrm{C} 57 \mathrm{BL} / 6 \mathrm{~J}$ mice (Ohn et al., 2016), CtBP2 immunofluorescence intensity, on average, was greater for pillar synapses (Fig. 8C). This difference could be related to different mouse strains (mixture of C57BL/6J and CD1 in this study) and/or to developmental stage analyzed as a similar spatial gradient to the one observed here was reported for CBA mice in the third postnatal week (Liberman and Liberman, 2016). In summary, the data indicate a decreased ribbon size in IHCs of the Atoh $1^{\text {cre }} ; P$ ou $4 \mathrm{fl}^{\text {flox/- }}$ Cochleae, whereas the gradient of ribbon size was comparable to IHCs of the control littermates. 

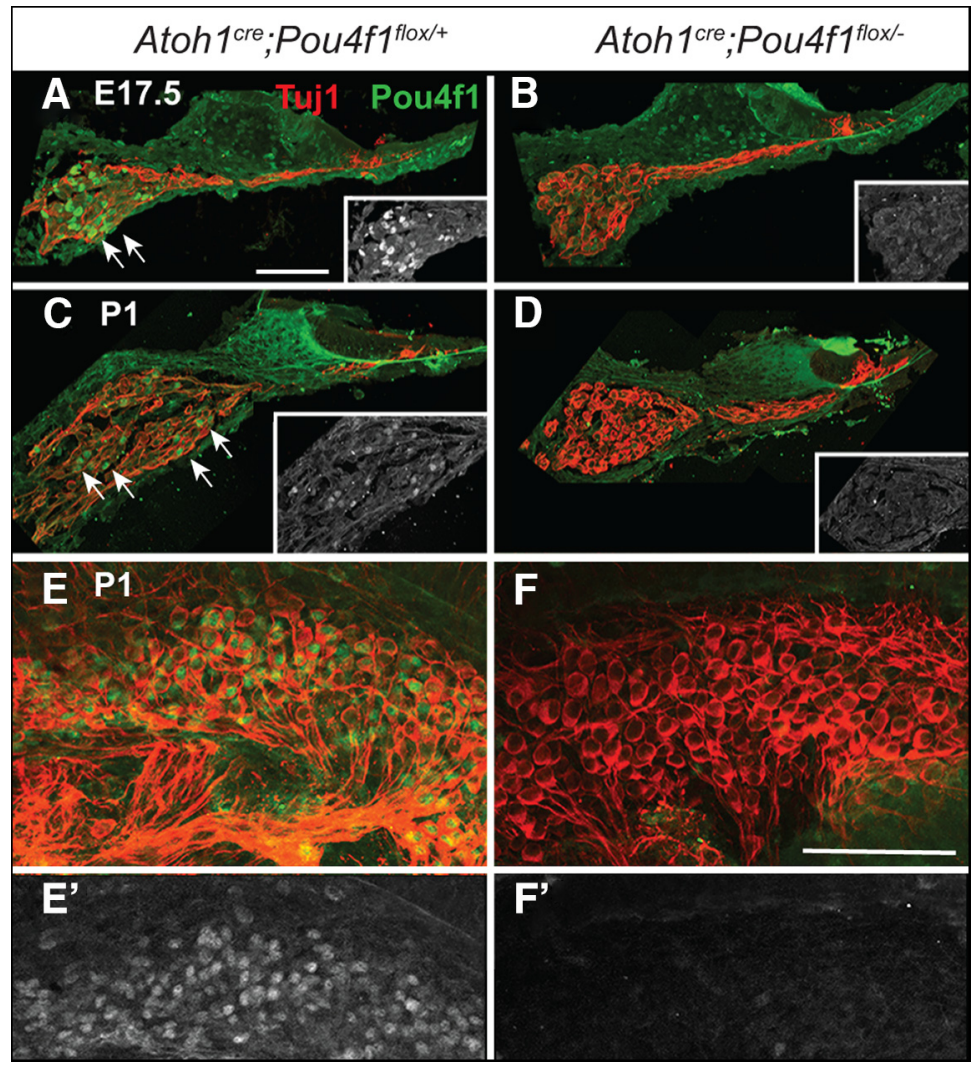

Figure 5. Ectopic Atoh $1^{\text {cre }}$ expression in SGN successfully deletes Pou4f1 by E17.5. $\boldsymbol{A}-\boldsymbol{D}$, Mid-modiolar cross-sections through the apical turns of cochleae at the indicated ages. SGNs are labeled with Tuj1. In control (Atoh $1^{\text {cre. } P o u 4 f 1^{\text {fl } /+}}{ }^{\text {) }}$, multiple SGNs are positive for Pou4f1 at both E17.5 and P1 (arrows). In contrast, in cochleae from Atoh $1^{\text {cre }}$;Pou4f ${ }^{\text {flox/ }}$ - mice, only weak (at E17.5) or no (at P1) expression of Pou4f1 is present in the SGN. Insets show Pou4f1 expression in the SGN in grayscale. $\boldsymbol{E}, \boldsymbol{F}$, Whole-mount views of the SG from the middle region of the cochlea at P1 labeled as in $A$. Many SGN nuclei express Pou $4 f 1$ in the control, but no Pou4f1 expression is observed in the Atoh ${ }^{\text {cre }} ;$;ou $4 f 1^{\text {flox } /-}{ }^{-} \cdot \boldsymbol{E}^{\prime}, \boldsymbol{F}^{\prime}$, Pou4f1 expression in grayscale. Scale bar in $\boldsymbol{A}$ (same as in $\left.\boldsymbol{B}-\boldsymbol{D}\right)$, $50 \mu \mathrm{m}$; scale bar in in $\boldsymbol{F}$ (same as in $\boldsymbol{E}$ ), $100 \mu \mathrm{m}$.

Atoh $1^{\text {cre }} ;$ Pou $4 \mathrm{f1} 1^{\text {flox/- }}$ mice exhibit an increased voltage sensitivity of the activation of $\mathrm{Ca}^{2+}$ influx at the whole-cell and single-synapse levels

Next, because the immunofluorescence intensity but not the position of the presynaptic ribbons was affected by the lack of Pou4f1 expression in type I SGNs, we examined a possible instructive trans-synaptic influence of this SGN subpopulation on the presynaptic $\mathrm{Ca}^{2+}$ influx in IHCs. We performed whole-cell patch-clamp recordings of presynaptic voltage-gated $\mathrm{Ca}^{2+}$ influx in IHCs ( $>90 \%$ of which is mediated by $\mathrm{Ca}_{\mathrm{V}} 1.3 \mathrm{Ca}^{2+}$ channels; Platzer et al., 2000; Brandt et al., 2003; Dou et al., 2004) from Atoh $1^{\text {cre }}$ Pou $4 \mathrm{f} 1^{\text {flox } /-}$ and control littermates (Atoh $1^{\text {cre }}$; Pou $4 \mathrm{f1}^{-{ }^{-+}}$) mice at 3 weeks of age (P21-P28). Using voltage-step depolarizations in conditions isolating the $\mathrm{Ca}^{2+}$ influx (see Materials and Methods), we probed its amplitude and voltage dependence (Fig. 9A). The amplitude of $\mathrm{Ca}^{2+}$ influx (Fig. 9A $)$ was unaltered in Atoh $1^{\text {cre }}$;Pou 4 f1 $1^{\text {flox/- }}$ mice $(-173 \pm 6 \mathrm{pA}, \mathrm{SD}=38$ $\mathrm{pA}, n=44$ IHCs, $N=14$ in Atoh $1^{\text {cre }}$;Pou $4 \mathrm{fl} 1^{\text {flox } /-}$ vs $-161 \pm 7$ $\mathrm{pA}, \mathrm{SD}=49 \mathrm{pA}, n=44$ IHCs, $N=16$ in control; $p=0.20$, Student $t$ test). We then analyzed the voltage dependence of $\mathrm{Ca}^{2+}$ channel activation (Fig. 9B) and found a small but significant hyperpolarizing shift of the potential of half-maximal $\mathrm{Ca}^{2+}$ channel activation, $V_{\mathrm{h}}$ (Fig. $9 B_{i},-24.95 \pm 0.47 \mathrm{mV}, \mathrm{SD}=3.11$ $\mathrm{mV}, n=44 \mathrm{IHCs}, N=14$ in Atoh $1^{\text {cre }}$ Pou $4 \mathrm{fl} 1^{\mathrm{flox} /-}$ mice vs $-23.30 \pm 0.60 \mathrm{mV}, \mathrm{SD}=3.96 \mathrm{mV}, n=44 \mathrm{IHCs}, N=16 \mathrm{in}$
Atoh $1^{\text {cre }} ;$ Pou $4 \mathrm{f} 1^{-/+}$mice; $p=0.032$, Student $t$ test). This shift was primarily caused by an increased voltage sensitivity of $\mathrm{Ca}^{2+}$ channel activation (reflected by a decrease of the slope factor $k$ ) in Atoh $1^{\text {cre }}$; Pou $4 \mathrm{fl}^{\text {flox/- }}$ IHCs $(7.63 \pm 0.07 \mathrm{mV}, \mathrm{SD}=$ $0.45 \mathrm{mV}, n=44 \mathrm{IHCs}, N=14$ vs $7.97 \pm$ $0.10 \mathrm{mV}, \mathrm{SD}=0.65 \mathrm{mV}, n=44$ IHCs, $N=16$ in the control, $p=0.017$, MannWhitney-Wilcoxon test; Fig. $\left.9 B_{i i}\right)$. To measure the $\mathrm{Ca}^{2+}$ influx at single presynaptic AZs (Frank et al., 2009), we loaded the IHCs with a low-affinity $\mathrm{Ca}^{2+}$ indicator dye $(800 \mu \mathrm{M}$ Fluo-4FF) and used a spinning-disk confocal microscope that allows fast registering and recording of the majority of the IHC synapses (Ohn et al., 2016). We chose experimental conditions (addition of a $10 \mathrm{~mm}$ concentration of the synthetic $\mathrm{Ca}^{2+}$ chelator EGTA) in which the $\mathrm{Ca}^{2+}$ indicator fluorescence is a proxy for the $\mathrm{Ca}^{2+}$ influx (Frank et al., 2009; Ohn et al., 2016; Jean et al., 2018). Before analysis of $\mathrm{Ca}^{2+}$ influx, we imaged fluorescently conjugated CtBP2-binding peptide (Zenisek et al., 2004), which allowed us to identify the ribbon-type AZs. We then used ramp depolarizations to assess amplitude and voltage dependence of $\mathrm{Ca}^{2+}$ influx from the bottom-most to the topmost ribbon (from basal to nuclear level of the IHC; see Materials and Methods). For simplicity, we refer to "synaptic $\mathrm{Ca}^{2+}$ influx" when describing observations based on hotspots of $\mathrm{Ca}^{2+}$ indicator fluorescence colocalizing with a marked ribbon at the basolateral IHC membrane. We found comparable maximal amplitudes of the background-normalized maximal fluorescence increase be-

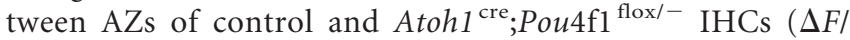
$F_{\max } ; 0.86 \pm 0.03, \mathrm{SD}=0.44, n=203 \mathrm{AZs}$ in $20 \mathrm{IHCs}, N=10$ in Atoh $1^{\text {cre }} ;$ Pou $4 \mathrm{f} 1^{\text {flox } /-}$ vs $0.88 \pm 0.03, \mathrm{SD}=0.45, n=155$ AZs in 17 IHCs, $N=9$ in controls, $p=0.46$, Mann-WhitneyWilcoxon test; Fig. $9 C_{i}$ ). This indicates an unchanged number of synaptic $\mathrm{Ca}^{2+}$ channels at IHC AZs in Atoh $1^{\mathrm{cre}} ; \mathrm{Pou} 4 \mathrm{f} 1^{\text {flox/- }}$ animals and agrees with the observation of unchanged wholecell $\mathrm{Ca}^{2+}$ current amplitudes.

Next, we analyzed the voltage dependence of activation for the synaptic $\mathrm{Ca}^{2+}$ influx as described previously (Ohn et al., 2016; Jean et al., 2018). Analysis of fractional activation revealed a slight tendency for the $V_{\mathrm{h}}$ to be shifted toward more hyperpolarized potentials in Atoh $1^{\text {cre }} ;$ Pou $4 \mathrm{fl}^{\text {flox/- }}$ IHCs that did not reach significance $(-25.54 \pm 0.45 \mathrm{mV}, \mathrm{SD}=5.80 \mathrm{mV}, n=168 \mathrm{AZs}$ in 20 IHCs, $N=10$ in the Atoh $1^{\text {cre }}$;Pou $4 \mathrm{f} 1^{\text {flox } /-}$ vs $-24.11 \pm 0.61 \mathrm{mV}$, $\mathrm{SD}=7.20 \mathrm{mV}, n=139 \mathrm{AZs}$ in $17 \mathrm{IHCs}, N=9$ in the control, $p=$ 0.13, Mann-Whitney-Wilcoxon test; Fig. $9 D_{i}$ ). As for the wholecell $\mathrm{Ca}^{2+}$ influx, the voltage sensitivity was subtly but significantly increased on the single AZ level $(6.66 \pm 0.12 \mathrm{mV}, \mathrm{SD}=$ $1.58 \mathrm{mV}, n=168$ AZs in 20 IHCs, $N=10$ in the Atoh1 ${ }^{\text {cre; }}$; Pou4f1 ${ }^{\text {flox/- }}$ vs $7.05 \pm 0.16 \mathrm{mV}, \mathrm{SD}=1.92 \mathrm{mV}, n=139$ AZs in 17 IHCs, $N=9$ in the control, $p=0.045$, Mann-Whitney-Wilcoxon test; Fig. $\left.9 D_{i i}\right)$. 

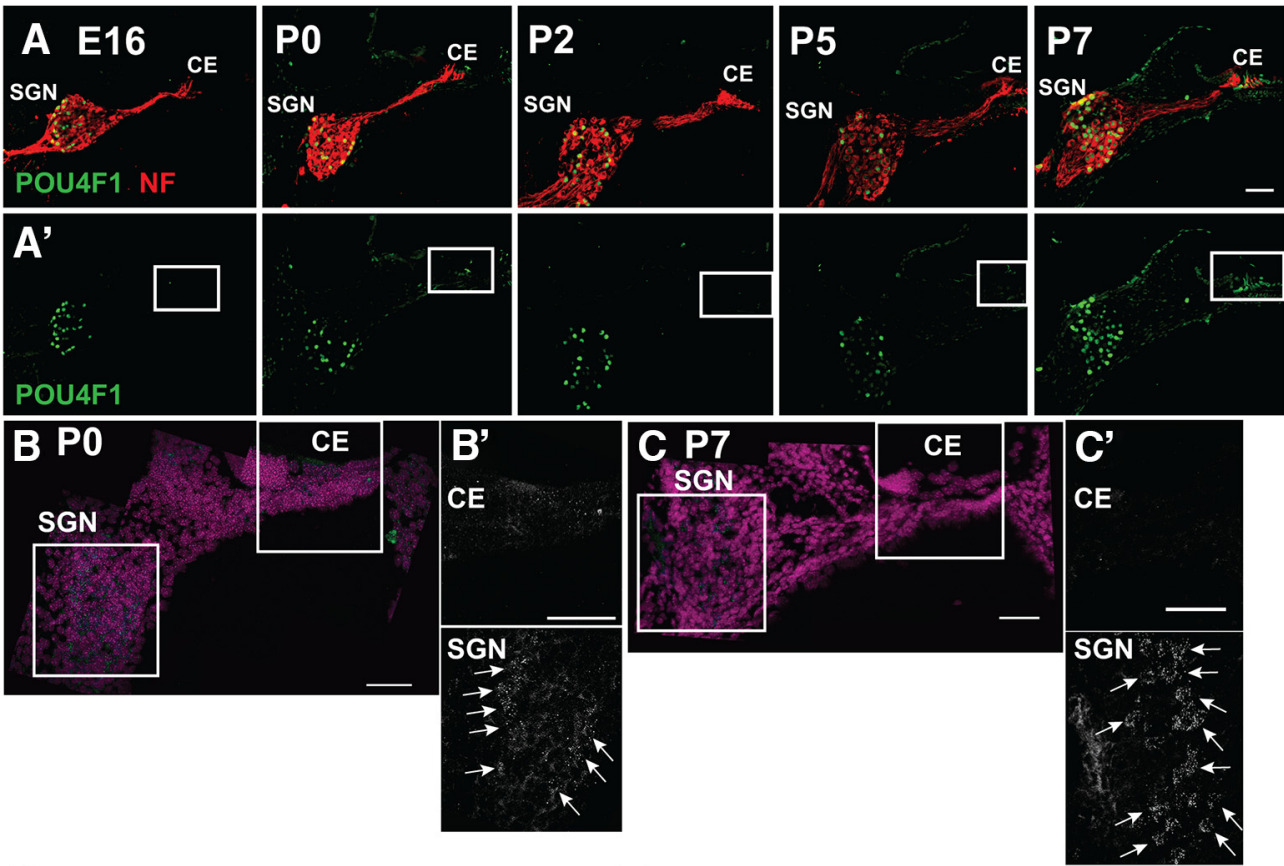

D

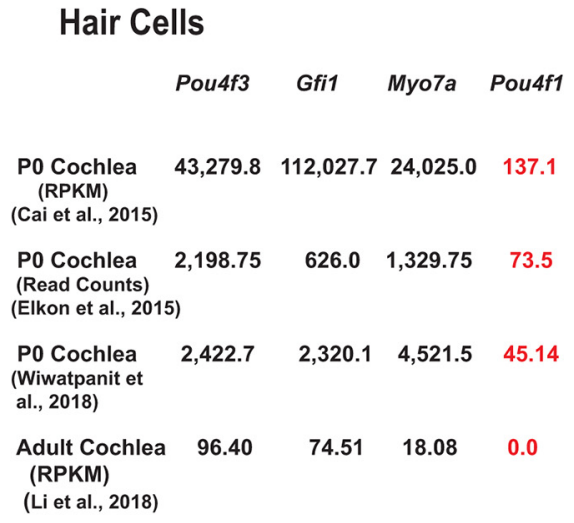

$E$

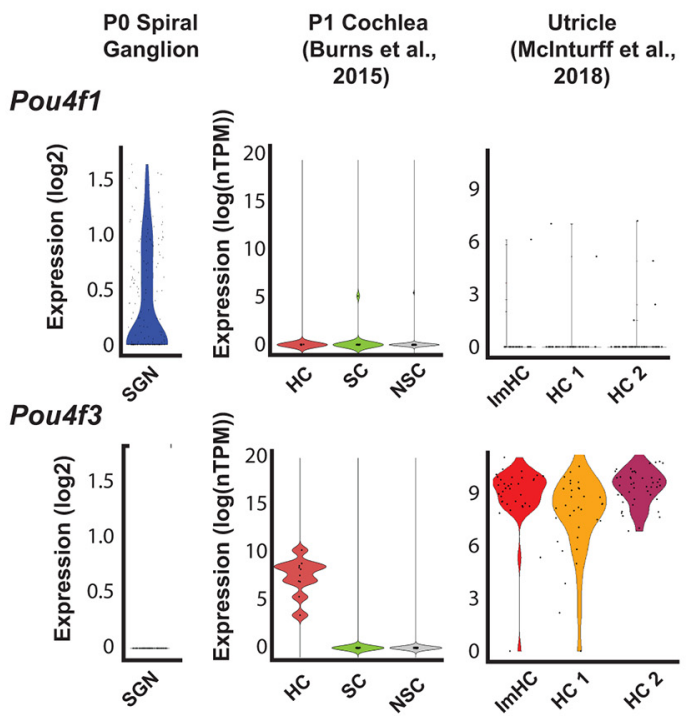

Figure 6. Pou4f1/POU4F1 is not expressed in hair cells. $A$, Cross-sections through the basal turn of the cochlea at the indicated ages immunostained with anti-POU4F1 (green) and antiNEUROFILAMENT (NF in red). POU4F ${ }^{+}$nuclei are present in the spiral ganglia at all ages. In contrast, no expression of POU4F1 is present in any hair cell (HC) nuclei. $\boldsymbol{A}^{\prime}$, Same images as in $\boldsymbol{A}$, but with only POU4F1 expression illustrated. The hair cell region in each section is boxed. $\boldsymbol{B}$, Cross-section through the basal turn of the cochlea at P0. Expression of Pou4f1 is detected using a fluorescent RNAscope probe (green puncta). Cell nuclei are labeled in magenta. Green Pou4f1 ${ }^{+}$puncta are present in the boxed SGN region but are not present in the boxed $\mathrm{HC}$ region. $\boldsymbol{B}^{\prime}$, High-magnification images of the boxed regions in $\boldsymbol{B}$ showing only the RNAscope signal. Pou4f1 ${ }^{+}$puncta are present in SGN nuclei (arrows), but no labeling is present in the hair cells. $\boldsymbol{C}, \boldsymbol{C}^{\prime}$, Similar views as in $\boldsymbol{B}$ and $\boldsymbol{B}^{\prime}$ but for a P7 cochlea. As at PO, numerous Pou $4 f_{1}{ }^{+}$puncta are present in the SGN nuclei but no puncta are observed in the hair cell region. $\boldsymbol{D}$, Summary of gene expression in hair cells from published studies (data obtained, in part, from gEAR). Expression of three genes known to be expressed in hair cells (Pou4f3, Gfi1, and Myo7a) and Pou4f1 (red) were examined in four recently published RNAseq datasets. In each case, the expression level for Pou $4 f 1$ is two orders of magnitude lower than at least one of the known hair-cell-specific genes. $E$, Expression of Pou $4 f 1$ by single-cell RNAseq. Violin plots illustrate the probability distribution for Pou4f1 and Pou4f3 expression in single cells isolated from the indicated tissues. At P0, Pou4f1 is detected in a subset of SGNs, consistent with antibody and RNAscope results, whereas Pou4f3 is not detected. In contrast, isolated P1 cochlear hair cells (Burns et al., 2015) express Pou4f3 but not Pou4f1. Similarly, isolated utricular hair cells (pooled from P1, P12, and P100; McInturff et al., 2018) are also positive for Pou4f3 but negative for Pou4f1. CE, Cochlear epithelium; SC, cochlear supporting cell; NSC, cochlear nonsensory cell; ImHC, immature utricular hair cell; $H C 1$, type 1 utricular hair cell; $H C 2$, type 2 utricular hair cell. Scale bar in $\boldsymbol{A}$ (same for $\boldsymbol{A}^{\prime}$ ), $50 \mu \mathrm{m}$; scale bars in $\boldsymbol{B}, \boldsymbol{B}^{\prime}, \boldsymbol{C}$, and $\boldsymbol{C}^{\prime}, 50 \mu \mathrm{m}$.

\section{Changes in the position dependence of $\mathrm{AZ}$ properties in} Atoh $1^{\text {cre }}$;Pou $4 \mathrm{fl}^{\text {flox/- }}$ IHCs

Because Pou4f1 is expressed only in a subset of modiolar-targeted SGNs, likely representing low-spontaneous-rate, high-threshold SGNs, we assessed whether the changes in presynaptic $\mathrm{Ca}^{2+}$ influx observed upon postsynaptic Pou4f1 disruption depend on position along the modiolar-pillar axis. To study the position- dependent properties of the AZs of multiple IHCs, we reconstructed the IHCs in cylindrical coordinates and identified the positions of their synapses (for more details, see Materials and Methods and Ohn et al., 2016). It has been previously shown that the synapses located on the modiolar side present stronger $\mathrm{Ca}^{2+}$ influx (Meyer et al., 2009; Ohn et al., 2016), stronger ribbons, and more depolarized activation of the $\mathrm{Ca}_{\mathrm{V}} 1.3$ channels compared 


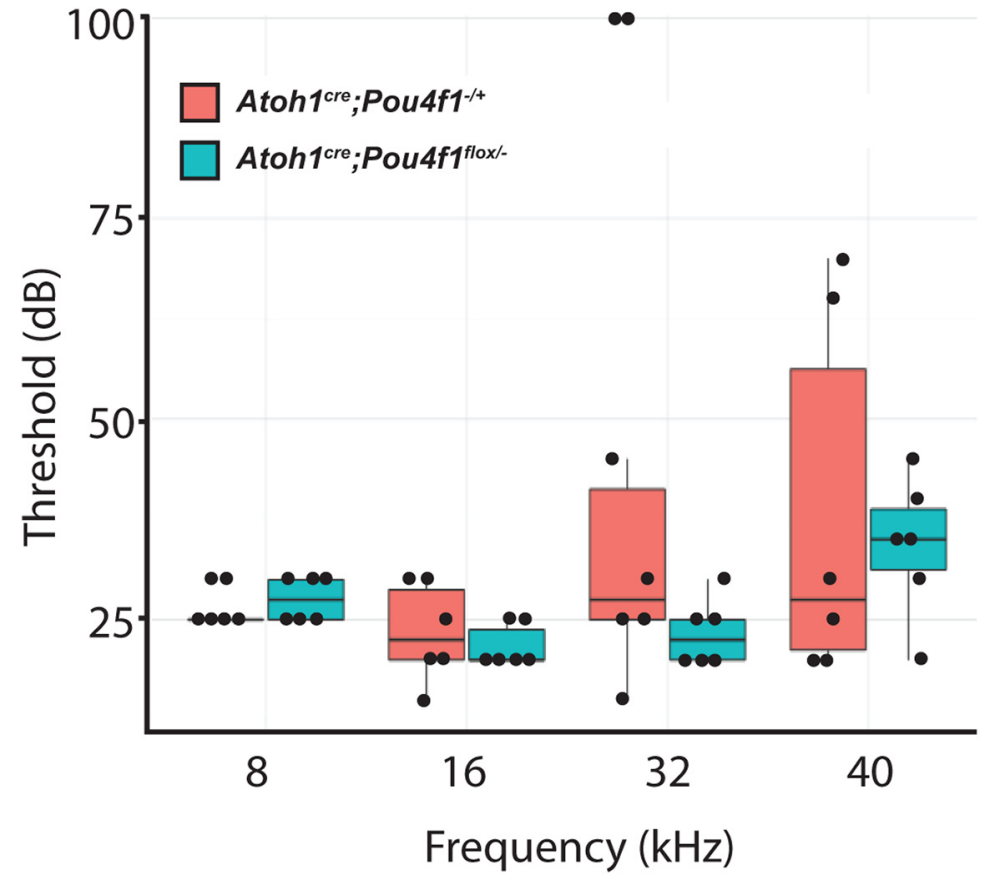

Figure 7. ABRs are normal in Atoh $1^{\text {cre }} ;$ Pou $4 f 1^{\text {flox/ }}$ - mice. ABR thresholds for 1-month-old control (red) and Atoh ${ }^{\text {cree; }}$; Pou4f1 flox/ - mice (green) at the indicated frequencies. No differences were observed between control and mutant animals.
$0.88 \pm 0.04 ., \mathrm{SD}=0.46, n=130 \mathrm{AZs}$ vs pillar: $0.80 \pm 0.07, \mathrm{SD}=0.40$, $n=73 \mathrm{AZs}$ in $20 \mathrm{IHCs}, N=10$, $p=0.38$, Mann-Whitney-Wilcoxon test; Fig. $11 A, B)$.

The AZ with the strongest $\Delta F_{\max } / F_{0}$ for a given cell, nicknamed "winner" (highlighted in blue in Fig. 11A) strongly contributes to the observed difference in $\Delta F_{\text {max }} / F_{0}$ between modiolar and pillar AZs in control IHCs. Consistent with this, the vast majority of winner synapses were located on the modiolar side for both control and Atoh $1^{\text {cre }}$;Pou $4 \mathrm{f} 1^{\text {flox/- }}$ animals (15 IHCs out of 17 IHCs for the control, 17 IHCs out of 20 IHCs for the Atoh $1^{\text {cre }}$; Pou $\left.4 \mathrm{f} 1^{\text {flox } /-}\right)$. The ratio mean $\Delta F_{\text {max }} / F_{0}$ of winner/mean $\Delta F_{\max } / F_{0}$ of the rest of the AZs (for a given cell) tended to be more pronounced in Atoh $1^{\text {cre }} ; P$ ou $4 \mathrm{fl}^{\text {flox/- }}$ compared with control $(2.07 \pm 0.13$ in Atoh $1^{\text {cre }} ; P$ ou $4 \mathrm{fl}{ }^{\text {flox/- }}$ vs $1.79 \pm 0.14$ in the control, $p=0.07$, Student $t$ test). Interestingly, when we compared $\Delta F_{\max } / F_{0}$ of modiolar and pillar AZs without the winners, there was still a tendency for stronger $\Delta F_{\text {max }} / F_{0}$ of AZs at the modiolar side of with synapses on the pillar side, which show opposite properties (Ohn et al., 2016). Consistent with the above immunolabeling result (Fig. 8), live imaging presented weaker fluorescence of the CtBP2-binding peptide for AZs on the modiolar side than the pillar side AZs in both genotypes (Atoh $1^{\text {cre }}$;Pou $4 \mathrm{fl}{ }^{\text {flox/- }}$ : modiolar: $2.67 \pm 0.09, \mathrm{SD}=1.02, n=137 \mathrm{AZs}$ vs pillar: $3.26 \pm 0.14$, $\mathrm{SD}=1.22, n=76 \mathrm{AZs}, N=10 ; p=0.00007$; control: modiolar: $2.28 \pm 0.07 ., \mathrm{SD}=0.72, n=119$ AZs vs pillar: $2.78 \pm 0.13 ., \mathrm{SD}=$ $0.93, n=52$ AZs in 17 IHCs, $N=9$; $p=0.00006$, Mann-Whitney-Wilcoxon test for both conditions; Fig. 10). In contrast to the immunofluorescence analysis, we found that, on average, CtBP2binding peptide labeling of ribbons was significantly stronger in IHCs in Atoh $1^{\text {cre }}$;Pou4f $1^{\text {flox/- }}$ compared with control (control: $2.43 \pm 0.06, n=171 \mathrm{AZs})$ vs Atoh $1^{\text {cre }} ;$ Pou $4 f 1^{\text {flox } /-}: 2.88 \pm 0.08$, $n=213$ AZs, $p=0.00002$, Mann-Whitney-Wilcoxon test) (Fig. $10 A$ ), in contrast to CtBP2 immunostaining data, where Atoh $1^{\text {cre }}$; Pou4f1 ${ }^{\text {flox/- }}$ IHCs presented significantly weaker ribbons at P14 (Fig. 8). In both, Atoh $1^{\mathrm{cre}} ;$ Pou $4 \mathrm{fl} 1^{\text {flox } /-}$ and control IHCs (Atoh ${ }^{\text {cre }} ;$ Pou $4 f 1^{-1+}$ ) the AZs of the modiolar side exhibited a slightly more depolarized activation of $\mathrm{Ca}^{2+}$-channels compared with the pillar side $\left(\right.$ Atoh $1^{\text {cre }} ;$ Pou 4 f1 ${ }^{\text {flox/- }}$, modiolar: $-24.61 \pm$ $0.54 \mathrm{mV}, \mathrm{SD}=5.62 \mathrm{mV}, n=108 \mathrm{AZs}$ vs pillar: $-27.21 \pm 0.74$ $\mathrm{mV}, \mathrm{SD}=5.78 \mathrm{mV}, n=60 \mathrm{AZs}$ in $20 \mathrm{IHCs}, N=10 ; p=0.011$; control: modiolar: $-23.05 \pm 0.71 \mathrm{mV}, \mathrm{SD}=6.95 \mathrm{mV}, n=96$ AZs vs pillar: $-26.47 \pm 1.12 \mathrm{mV}, \mathrm{SD}=7.32 \mathrm{mV}, n=43 \mathrm{AZs}, N=$ 9; $p=0.0056$, Mann-Whitney-Wilcoxon test for both conditions; Fig. 10B).

Finally, in agreement with our previous studies (Meyer et al., 2009; Ohn et al., 2016), we found that the AZs on the modiolar side of each IHC show a stronger $\Delta F / F_{0}\left(\Delta F_{\max } / F_{0}\right.$, mean of 5 values at the peak) compared with $A Z s$ on the pillar side in control IHCs (modiolar: $0.92 \pm 0.05, \mathrm{SD}=0.47, n=106 \mathrm{AZs}$ vs pillar: $0.79 \pm 0.06, \mathrm{SD}=0.39, n=49 \mathrm{AZs}$ in $17 \mathrm{IHCs}, N=9, p=$ 0.049, Mann-Whitney-Wilcoxon test; Fig. $11 A, B)$. In contrast, there was no significant difference in $\Delta F_{\max } / F_{0}$ along the modiolar-pillar axis in the Atoh $1^{\text {cre }} ;$ Pou $4 \mathrm{f} 1^{\text {flox } /-}$ IHCs (modiolar: control IHCs (modiolar: $0.83 \pm 0.03, n=91$ AZs vs pillar: $0.78 \pm$ $0.05,47 \mathrm{AZs}$ in $17 \mathrm{IHCs}, p=0.20$ ), whereas no such trend remained in Atoh $1^{\text {cre }} ;$ Pou $4 \mathrm{f} 1^{\text {flox/- }}$ animals (modiolar: $0.78 \pm 0.03$, $n=113 \mathrm{AZs}$ ) vs pillar: $0.79 \pm 0.05, n=70 \mathrm{AZs}$ in $20 \mathrm{IHCs}, p=$ 0.98; Fig. $11 A, B)$.

\section{Discussion}

In this study, we identified Pou4f1 as a marker for a subpopulation of type I SGNs. These findings are consistent with the results of three recent studies using single-cell mRNA profiling to examine cell types in the spiral ganglion of young adult mice. By tracing individual Pou4f1-expressing neurons using a combination of immunolabeling for Pou4f1 and sparse reporter labeling using the $N g n 1^{\text {creErt2 }} ; R 26 R^{\text {tdtomato }}$ mouse, we found that these cells overwhelmingly ( $96 \%$ confidence interval $=88-100 \%, n=24$ cells, $p=1.43 \times 10^{-6}$, binomial test) synapse on the modiolar reported in Petitpré et al. (2018) at more mature time points. These results suggest that Pou4f1 expression corresponds with a group of low-spontaneous-rate fibers. Combining Pou4f1 disruption with physiological and morphological analysis of IHC AZs, we propose that Pou4f1-positive SGNs instruct presynaptic properties.

\section{Deletion of Pou $4 \mathrm{fl}$ causes changes in presynaptic $\mathrm{AZ}$ properties}

Deletion of Pou $f 1$ using the ectopic Atoh $1^{\text {cre }}$ mouse line shortly after SGNs become postmitotic leads to two interesting physiological changes at IHCs: first, there was a subtle but significant increase in voltage sensitivity of the $\mathrm{Ca}^{2+}$ channel activation (on both the whole-cell and single-synapse levels), inducing a small hyperpolarizing shift of the voltage potential of half-maximal $\mathrm{Ca}^{2+}$ channel activation $\left(V_{\mathrm{h}}\right.$, significant on the level of whole-cell $\mathrm{Ca}^{2+}$ influx). Because it was shown in the cat that the modiolar IHC side is associated with low-spontaneous-rate, high-threshold SGNs (Liberman, 1982; Merchan-Perez and Liberman, 1996), we side of the IHC at P3, a result that is consistent with the findings 
A
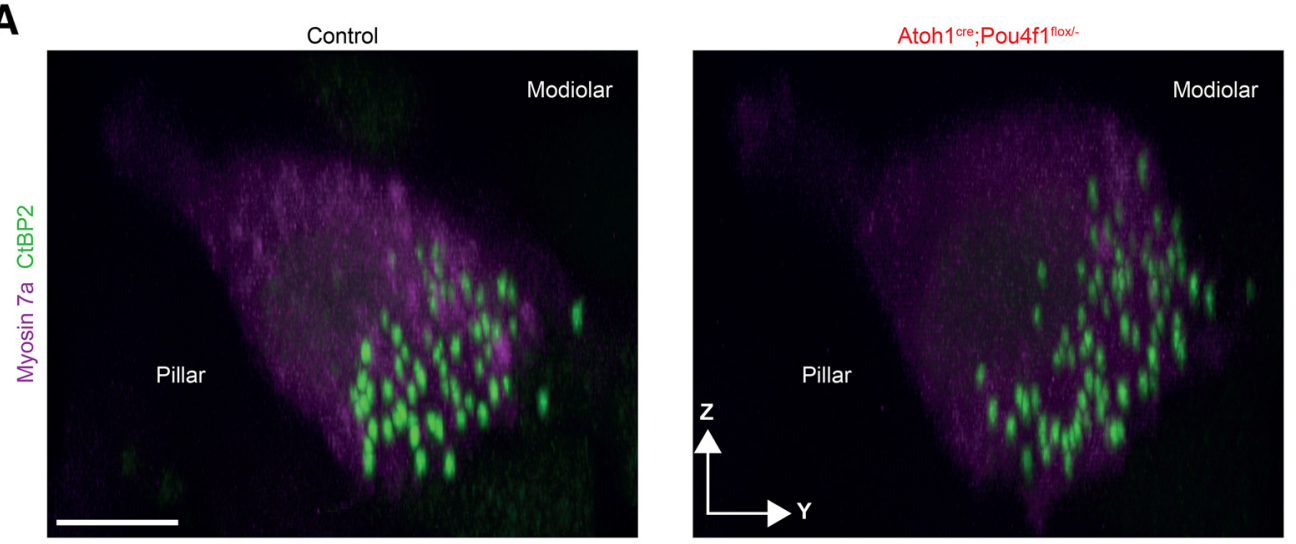

B

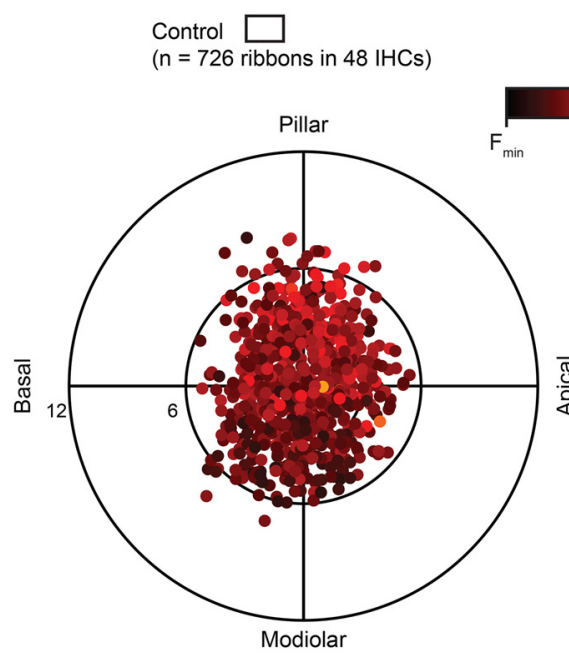

C
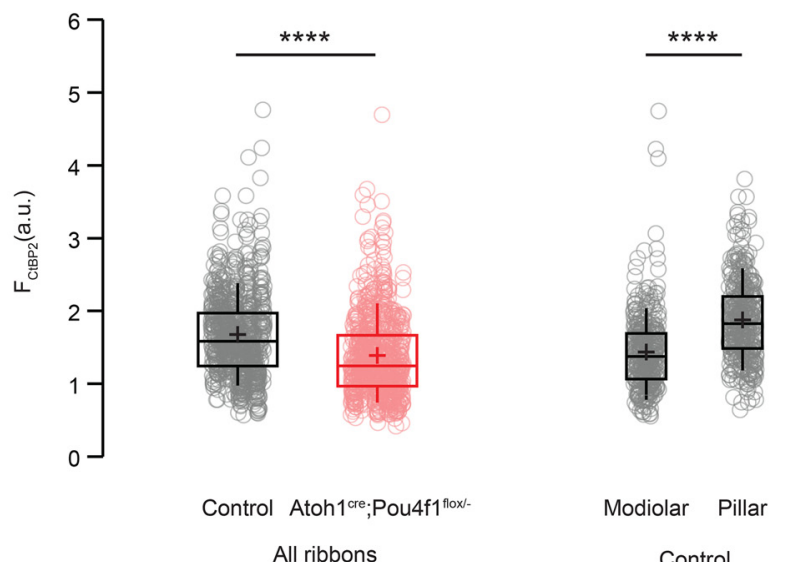

Atoh $1^{\text {cre }} ;$ Pou 4 f $1^{\text {flox } / \text { - }}$

( $n=720$ ribbons in $46 \mathrm{IHCs})$

$\mathrm{F}_{\mathrm{CtBP2}}$

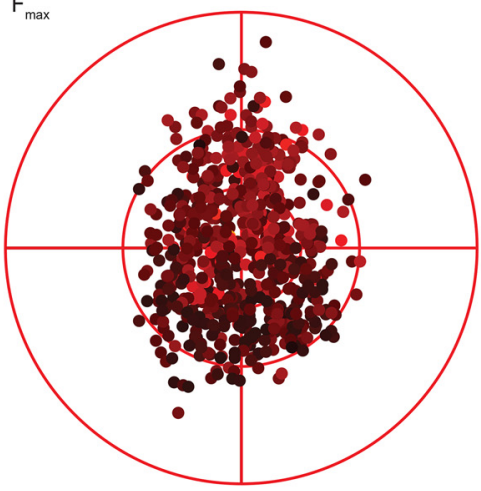

Control Atoh $1^{\text {cre }} ;$ Pou $4 \mathrm{f}^{\text {flox }}$

Control

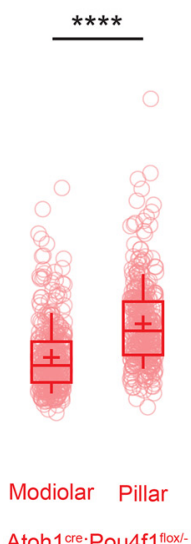

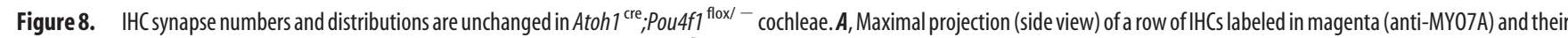

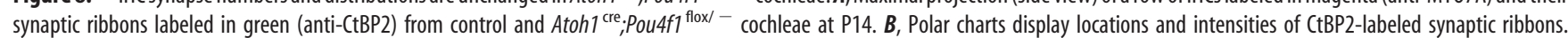
Orientations are indicated. C, Quantification of CtBP2 fluorescence intensity. Compared with control, synapses in Atoh ${ }^{\text {(re }}$;Pou4f ${ }^{\text {flox } /-}$ cochlea show decreased overall CtBP2 labeling intensity, suggesting decreased ribbon size in IHCs of the mutants ( $n=726$ ribbons from $48 \mathrm{IHCs}$ in control and 720 ribbons from $46 \mathrm{IHCs}$ in Atoh $7^{\text {cree }}$; Pou4f flox $/-^{-} ; p<0.0001$, Mann-Whitney-Wilcoxon test). For both control and Atoh $7^{\text {cre }}$;Pou $4 f^{f}{ }^{\text {flox } /}$ - IHCs, a significant gradient of ribbon size was observed along the pillar-modiolar axis (control: modiolar: $n=360$ spots; pillar: $n=376$ spots; Atoh $1^{\text {cre }}$;Pouff1 ${ }^{\text {flox/- }}$ : modiolar: $n=366$ spots; pillar: $n=354$ spots, $p<0.0001$, Mann-Whitney-Wilcoxon test for both conditions). Box plots show 10th, 25th, 50 th, 75 th, and 90 th percentiles, with individual data points overlaid. Means are shown as crosses. Scale bar in $A, 5 \mu \mathrm{m} .{ }^{* * * *} p<0.0001$.

speculate that Pou4f1 expression in SGNs might contribute to this phenotype through several possible mechanisms, including a trans-synaptic lowering of the voltage sensitivity of $\mathrm{Ca}^{2+}$ channel activation at the presynaptic IHC AZ. Clearly, the shift in voltage sensitivity is subtle and might not fully account for the physiological phenotype of low-spontaneous-rate SGNs, which is likely to require additional regulators (Ohn et al., 2016; Jean et al., 2018). In these previous studies, shifts in the voltage dependence of presynaptic $\mathrm{Ca}^{2+}$ influx of only a few millivolts correlated with changes in the distribution of the spontaneous rate in SGNs, which was not investigated here. However, it is important to consider that Pou $4 \mathrm{fl}$ is only expressed in $30 \%$ of all type I SGNs 


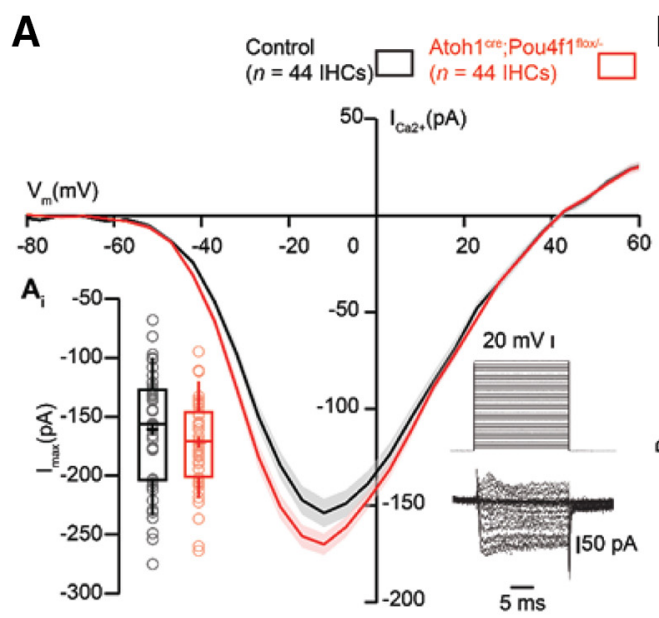

B
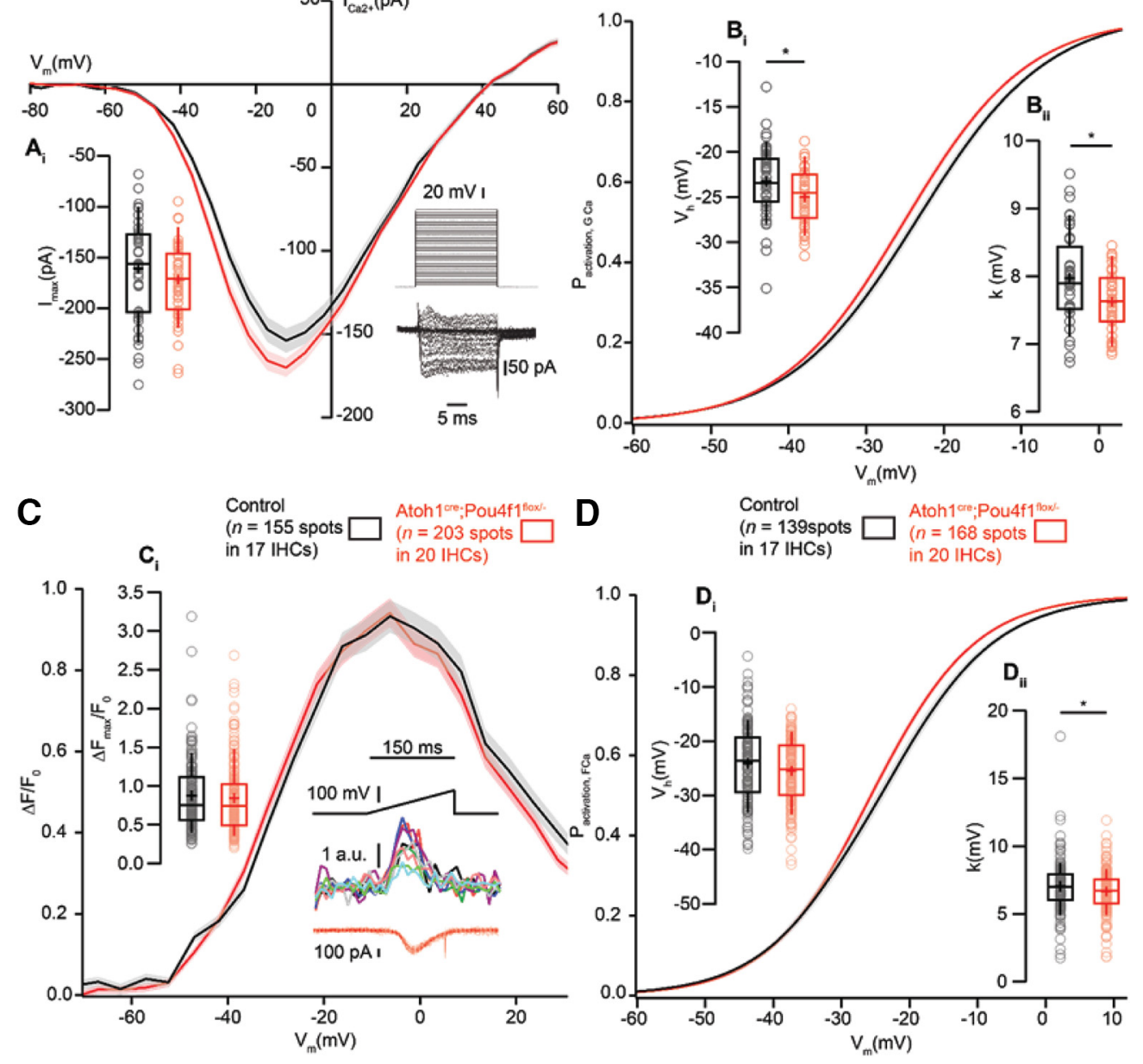

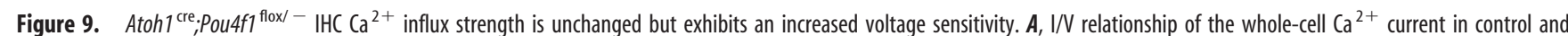

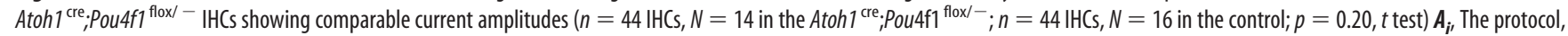
consisting of $20 \mathrm{~ms}$ steps of $5 \mathrm{mV}$ from $-82 \mathrm{to}+63 \mathrm{mV}$, as well as the resulting currents, are shown in the bottom right. Mean (line) \pm SEM (shaded areas) are displayed, the box plots show 10 , $25,50,75$, and 90 th percentiles with individual data points overlaid and means are shown as crosses, as for $\boldsymbol{B}-\boldsymbol{D}$. $\boldsymbol{B}$, Fractional activation of the whole-cell $\mathrm{Ca}^{2+}$ current derived from the $\mathrm{I} / \mathrm{V}$ relationships $(\boldsymbol{A})$ was fitted to a Boltzmann function. $\boldsymbol{B}_{i}$, Box plots of the voltage for half-maximal activation $V_{\mathrm{h}}$ and $V_{\mathrm{h}}$ estimates of individual IHCs showing a hyperpolarized shift of the fractional

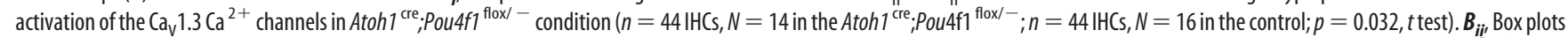

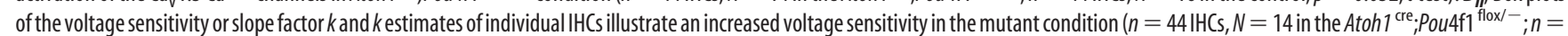
$44 \mathrm{IHCS}, N=16$ in the control; $p=0.017$, Mann-Whitney-Wilcoxon test). C, Voltage ramps from -87 to $+63 \mathrm{mV}$ during $150 \mathrm{~ms}$ (C, top right) were used to trigger synaptic hotspots of Fluo-4FF fluorescence ( $\boldsymbol{C}$, middle right, $10 \mathrm{AZs}$ in one exemplary $\mathrm{IHC}$ ), and IHC $\mathrm{Ca}^{2+}$ influx (middle bottom). FV relationship $\left(\Delta F / F_{0}\right.$ vs depolarization level in ramp) approximating the voltage dependence of synaptic $\mathrm{Ca}^{2+}$ influx. $C_{i} . \Delta F_{\text {max }} / F_{0}$ was calculated by averaging 5 values at the $\mathrm{FV}$ peak and was comparable between control and $A$ toh $1^{\text {cre; }}, P o u 4 f 1^{\text {flox } /-}$ conditions $(n=203 \mathrm{AZs}$ in $20 \mathrm{lHCs}, N=$ 10 in the Atoh $7^{\text {cre }} ;$ Pou $4 f_{1}{ }^{\text {flox/ } /-} ; n=155 \mathrm{AZs}$ in $17 \mathrm{IHCS}, N=9$ in the control; $p=0.46$, Mann-Whitney-Wilcoxon test). $D$, Fractional activation curves derived from fits to the FV relationships ( $C$ )

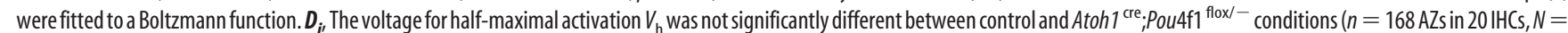

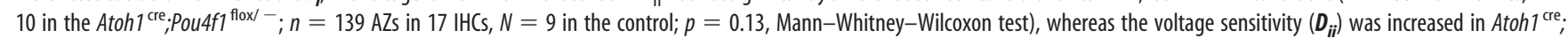

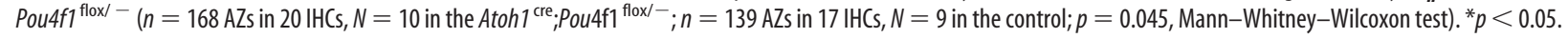

and not all modiolar-targeted SGNs. Therefore, 70\% of the synapses on any given IHC in a Atoh $1^{\text {cre }} ;$ Pou $4 f 1^{\text {flox/ }}$ cochlea may be phenotypically normal. Moreover, the argument relies on the assumption that these SGNs, in mice too, insert on the modiolar side of the IHC. Additionally, whereas Poutfi disruption leads to an overall hyperpolarized $\mathrm{Ca}^{2+}$ channel activation, the spatial gradient of the voltage dependence of $\mathrm{Ca}^{2+}$ channel activation was maintained. Therefore, more work, including recordings from single SGNs in Atoh ${ }^{\text {cre }} ; P$ Pou $4 f^{\text {flox/ - }}$ mice, remains to be done to comprehend the effects of the mutation and the molecular mechanisms determining SGN physiology.

Secondly, the modiolar-pillar gradient in maximal synaptic $\mathrm{Ca}^{2+}$ influx (“AZ strength") present in control IHCs was abol-

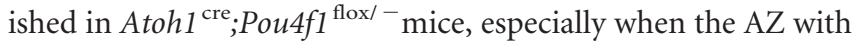
the strongest $\mathrm{Ca}^{2+}$ influx (the winner) was removed from the analysis. This suggests that Pou $4 \mathrm{fl}$ is not important in the formation of the $\mathrm{AZ}$ with the greatest $\mathrm{Ca}^{2+}$ channel complement, the winner. One interesting possibility is that the winner $\mathrm{AZ}$ is the first synaptic SGN contact engaged by an IHC independent of Pou4f1 expression and attracts the largest number of $\mathrm{Ca}^{2+}$ channels. However, Pou4f1 seems important in either establishing or maintaining the larger number of $\mathrm{Ca}^{2+}$ channels at the other modiolar AZs compared with those on the pillar side, which are not associated with Pou4f1-expressing SGNs. This instructive influence would set the maximal strength of the presynaptic release and might involve the differential recruitment of presynaptic 
A

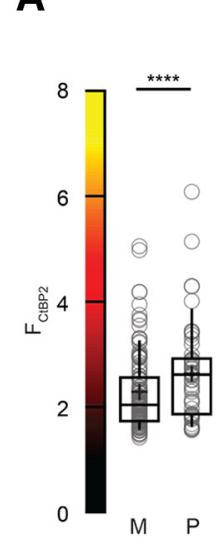

B

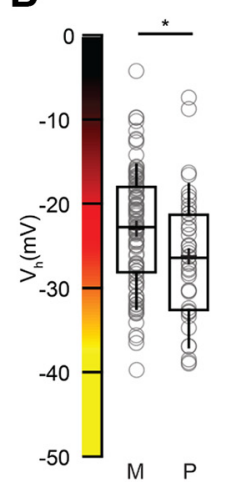

Control

$(n=171$ spots in $17 \mathrm{IHCs})$

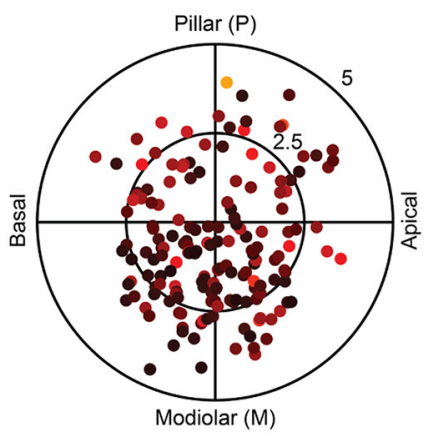

Control

( $n=139$ spots in $17 \mathrm{IHCs})$

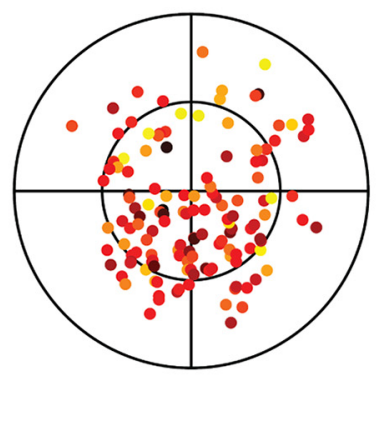

Atoh1 ${ }^{\text {cre }} ;$ Pou 4 f1 $1^{\text {flox }}$ -

$(n=213$ spots in $20 \mathrm{IHCs})$
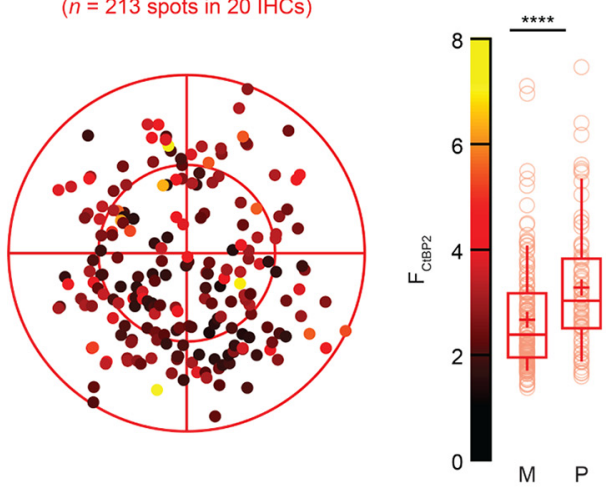

Atoh $1^{\text {cre }} ;$ Pou $4 \mathrm{f}^{\text {nox }}$ -

$(n=168$ spots in $20 \mathrm{IHCs})$
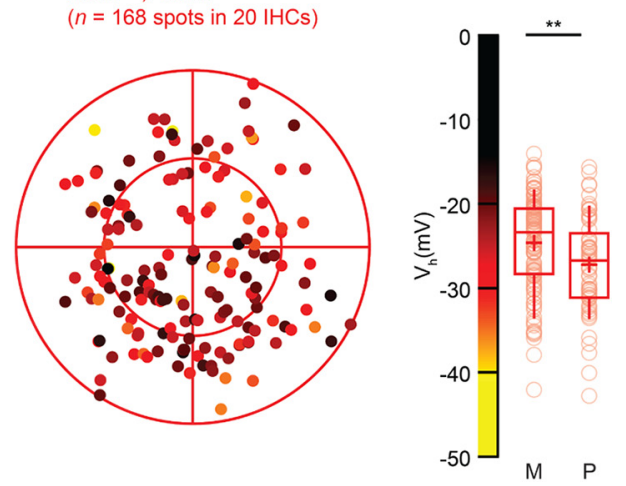

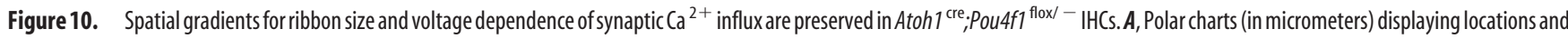
intensities of (tbp2-binding peptide (targeting the ribbons) fluorescence in live-imaging experiments. Box plots of the ribbon fluorescence $F_{\mathrm{CtBP2} 2}$ and $F_{\mathrm{CtBP2}}$ estimates of individual IHCs indicate that

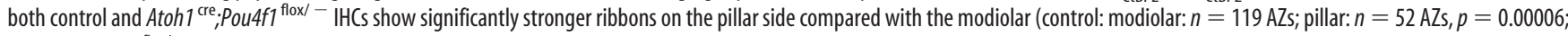

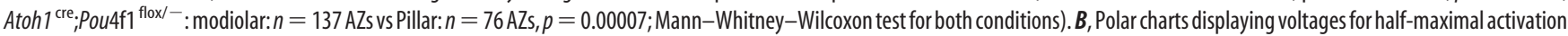
$V_{h}$ as a function of AZ positions in live-imaging experiments. Box plots of the voltage for half-maximal activation $V_{h}$ and $V_{h}$ estimates of individual IHCs show a significant hyperpolarized shift of the

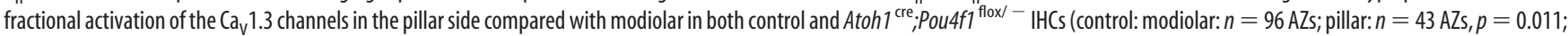

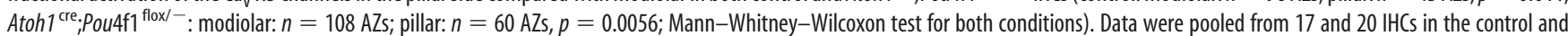
Atoh $7^{\text {cre }}$;Pou $4 f 1^{\text {flox } /-}$ conditions, respectively; box plots show 10 th, 25 th, 50 th, 75 th, and 90 th percentiles with individual data points overlaid; means are shown as crosses. ${ }^{*} p<0.05,{ }^{* *} p<0.01$ and ${ }^{* * *} p<0.0001$.

scaffolds, $\mathrm{Ca}^{2+}$ channel subunits, and proteins interacting with the $\mathrm{Ca}^{2+}$ channels potentially modulating the voltage dependence. Future studies will be required to test this hypothesis. Interestingly, a similar phenotype where the modiolar-pillar gradient of $\mathrm{Ca}^{2+}$ strength was collapsed despite a preserved gradient for its voltage dependence of activation was observed in IHC with defectuous intrinsic planar polarity. However the winner AZs were unaffected (Jean et al., 2019). A surprising finding was that of an inverted gradient of our proxies of ribbon size, where the stronger ribbons are found in the pillar side in both control and

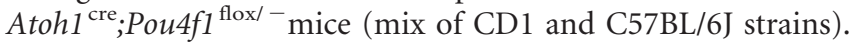
Both CtBP2 immunofluorescence and Ctbp2-binding peptide fluorescence intensity exhibited stronger signals, indicating larger ribbons, for pillar AZs in IHCs of both control and Atoh $1^{\text {cre }} ;$ Pou $4 \mathrm{f1}{ }^{\text {flox/- }}$ mice. The finding seems to be robust because it was made by two different methods (immunofluorescence and live imaging) and at two developmental stages (third and fourth postnatal weeks, respectively). Interestingly, a similar observation was made in the third postnatal week of CBA mice (Liberman and Liberman, 2016), with a gradient for larger synaptic ribbons on the pillar side, in contrast to our previous report at the same ages (Ohn et al., 2016, C57BL/6J). Nonetheless, future studies, ideally involving electron microscopy, should follow up on this observation over several devel- opmental stages (Liberman and Liberman, 2016; Michanski et al., 2019) and compare with previous studies on mouse cochleae from different mouse strains (Liberman et al., 2011; Liberman and Liberman, 2016; Ohn et al., 2016).

\section{Potential roles of Pou4f1 for postnatal SGN function}

Despite the physiological results, deletion of Pou ff1 using the ectopic Atoh $1^{\text {cre }}$ mouse did not have any effect on number of SGNs, overall SG development, or synaptic distribution. This result is not particularly surprising in light of a recent study exploring the role of Pou4f1 in the retina (Huang et al., 2014), in which a tamoxifen-inducible Cre was used to knock out Pou 41 after specification of retinal ganglion cells. The results from that study reported no change in ganglion cell number or morphology even 6 months after tamoxifen application. Furthermore, the conditional knock-out mice still showed expression of Vglut2, which shows correlated expression with Pou4f1 in both retina and cochlea (Sherrill and Kelley, unpublished data), suggesting that Pou4f1 may not be the sole or primary driver of cell identity in either retinal or spiral ganglion neurons.

Finally, although many studies have shown that synaptic location strongly correlates with spontaneous rate, as yet, there are no data proving how the two features are linked mechanistically. Given the strong correlation between Pou4f1 expression and syn- 
A

$$
\underset{(n=155 \text { spots in } 17 \text { IHCs })}{\square}
$$

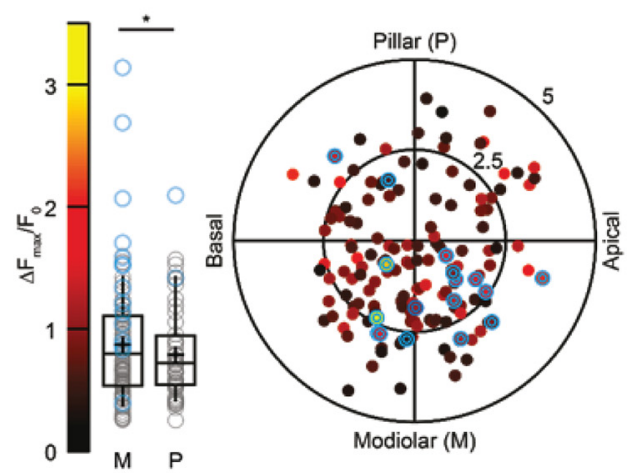

B

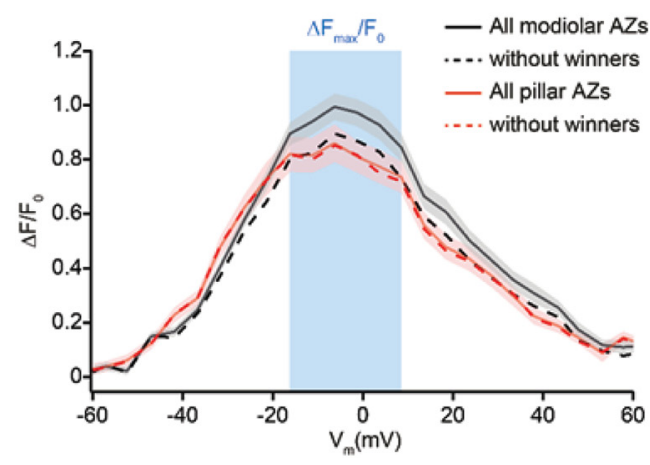

(.) "Winner" AZs: strongest $\Delta F_{\max ^{\prime}} / F_{0}$ for a given cell
Atoh 1 ere; Pou 4 f1 $1^{\text {nox }}$.

( $n=203$ spots in 20 IHCs)
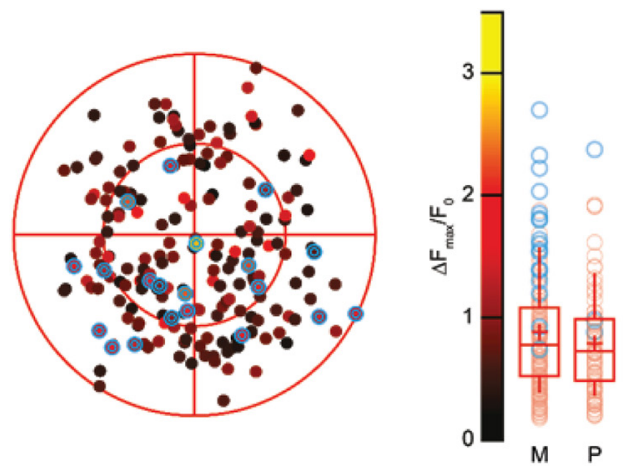

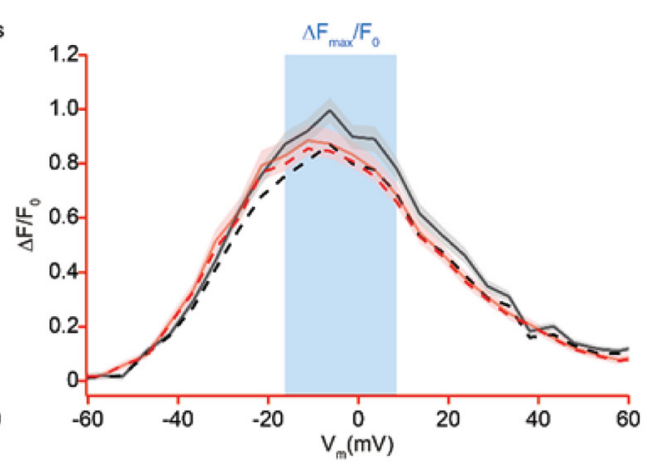

Figure 11. Spatial gradient for synaptic $\mathrm{Ca}^{2+}$ influx strength is collapsed in Atoh $1^{\text {cre }}$;Pou4f $1^{\text {flox } /-} \mathrm{HHCs}$. A, Polar charts (in micrometers) displaying intensities of maximal AZ Ca ${ }^{2+}$ influx $\left(\Delta F_{\text {max }} / F_{0}\right)$ as a function of AZ positions in live-imaging experiments. Box plots of the $\Delta F_{\text {max }} / F_{0}$ and $\Delta F_{\text {max }} / F_{0}$ estimates of individual IHCs show that control IHCs display significantly stronger calcium hotspots on the modiolar side compared with the pillar side (control: modiolar: $n=106 \mathrm{AZs}$; pillar: $n=49 \mathrm{AZs}, p=0.049$, Mann-Whitney-Wilcoxon test), whereas no significant differences in $\mathrm{Ca}^{2+}$ hotspot strength were observed in Atoh $7^{\text {cre }}$; Pou $4 f^{\text {flox } /-}$ IHCs (modiolar: $n=130 \mathrm{AZs}$; pillar: $n=73 \mathrm{AZs}, p=0.38$, Mann-Whitney-Wilcoxon test). The strongest AZs from each cell, the winners, are highlighted in blue in both polar charts and box plots. $B$, FV relationship ( $\Delta F / F_{0}$ vs depolarization level in ramp) approximating the voltage dependence of synaptic $C^{2+}$ influx in control (left) and Atoh $7^{\text {cre; }}$ Pou $f f^{\text {flox } /-}$ (right). The modiolar and pillar synaptic $\mathrm{Ca}^{2+}$ influx are black and red, respectively, and displayed as dashed lines when removing the winners. Data were pooled from 17 and $20 \mathrm{IHCs}$ in the control and Atoh $1^{\text {cre }}$;Pou $4 f 7^{\text {flox/ }}$ - condition, respectively. Mean (line) \pm SEM (shaded areas) are displayed, box plots show 10th, 25th, 50th, 75th, and 90th percentiles with individual data points overlaid; means are shown as crosses.

aptic location, a next logical step would be to characterize possible changes in the physiological responses of Pou4f1-deleted SGNs themselves. One possible way to approach this would be to use the Pou4f1 $1^{\text {creErt2 }}$ line to simultaneously delete Pou4f1 and fluorescently label the same neurons. However, in contrast to the results reported in Petitpré et al. (2018), we observed limited overlap between SGNs that were labeled in response to sparse induction of Pou $41^{\text {creErt2 }}$ and immunolocalization of Pou4f1. The differing results could be a function of the differences in timing of induction. For our experiments, induction occurred during the first postnatal week. In contrast, Petitpré et al. (2018) induced at $\sim$ P25. Further, it has not been determined whether the Pou $4 f_{1}{ }^{\text {creErt2 }}$ line faithfully recapitulates Pou $4 \mathrm{f} 1$ expression in other regions of the CNS. The original transgenic construct used only the upstream $11 \mathrm{~kb}$ region of Pou $4 \mathrm{fl}$, which leaves open the possibility for nonspecific activation as a result of the absence of more distant regulatory elements.

In conclusion, following an initial period of broad expression in all developing SGNs, Pou4f1 is downregulated in $\sim 70 \%$ of SGNs during the first postnatal week. The $30 \%$ of type I SGNs that maintain expression of Pou4f1 into adulthood predominantly form synapses on the modiolar sides of IHCs. This result suggests that Pou4f1 + SGNs probably represent a subgroup of low-spontaneous-rate, high-threshold fibers. Deletion of Pou ff 1 in SGNs leads to changes in the presynaptic AZs in IHCs, in particular causing a hyperpolarized activation range for their $\mathrm{Ca}^{2+}$ channels by increasing their voltage sensitivity. Although these results indicate an instructive role for postsynaptic SGNs in the function of presynaptic sites, more work remains to be done to elucidate the genetic factors that influence specification of physiologically distinct SGNs.

\section{References}

Badea TC, Cahill H, Ecker J, Hattar S, Nathans J (2009a) Distinct roles of transcription factors brn3a and brn $3 \mathrm{~b}$ in controlling the development, morphology, and function of retinal ganglion cells. Neuron 61:852-864.

Badea TC, Hua ZL, Smallwood PM, Williams J, Rotolo T, Ye X, Nathans J (2009b) New mouse lines for the analysis of neuronal morphology using CreER(T)/loxP-directed sparse labeling. PLoS One 4:e7859.

Badea TC, Williams J, Smallwood P, Shi M, Motajo O, Nathans J (2012) Combinatorial expression of Brn3 transcription factors in somatosensory neurons: genetic and morphologic analysis. J Neurosci 32:995-1007.

Brandt A, Striessnig J, Moser T (2003) CaV1.3 channels are essential for development and presynaptic activity of cochlear inner hair cells. J Neurosci 23:10832-10840.

Blanchard JW, Eade KT, Szúcs A, Lo Sardo V, Tsunemoto RK, Williams D, Sanna PP, Baldwin KK (2015) Selective conversion of fibroblasts into peripheral sensory neurons. Nat Neurosci 18:25-35.

Burns JC, Kelly MC, Hoa M, Morell RJ, Kelley MW (2015) Single-cell RNA- 
Seq resolves cellular complexity in sensory organs from the neonatal inner ear. Nat Commun 6:8557.

Cai T, Jen HI, Kang H, Klisch TJ, Zoghbi HY, Groves AK (2015) Characterization of the transcriptome of nascent hair cells and identification of direct targets of the Atoh1 transcription factor. J Neurosci 35:5870-5883.

Coate TM, Spita NA, Zhang KD, Isgrig KT, Kelley MW (2015) Neuropilin2/Semaphorin-3F-mediated repulsion promotes inner hair cell innervation by spiral ganglion neurons. Elife 4:e07830.

Deng M, Yang H, Xie X, Liang G, Gan L (2014) Comparative expression analysis of POU4F1, POU4F2 and ISL1 in developing mouse cochleovestibular ganglion neurons. Gene Expr Patterns 15:31-37.

Dou H, Vazquez AE, Namkung Y, Chu H, Cardell EL, Nie L, Parson S, Shin HS, Yamoah EN (2004) Null mutation of alpha1D Ca2+ channel gene results in deafness but no vestibular defect in mice. J Assoc Res Otolaryngol 5:215-226.

Elkon R, Milon B, Morrison L, Shah M, Vijayakumar S, Racherla M, Leitch CC, Silipino L, Hadi S, Weiss-Gayet M, Barras E, Schmid CD, Ait-Lounis A, Barnes A, Song Y, Eisenman DJ, Eliyahu E, Frolenkov GI, Strome SE, Durand, et al. (2015) RFX transcription factors are essential for hearing in mice. Nat Commun 6:8549.

Frank T, Khimich D, Neef A, Moser T (2009) Mechanisms contributing to synaptic $\mathrm{Ca}^{2+}$ signals and their heterogeneity in hair cells. Proc Natl Acad Sci U S A 106:4483-4488.

Hua ZL, Emiliani FE, Nathans J (2015) Racl plays an essential role in axon growth and guidance and in neuronal survival in the central and peripheral nervous systems. Neural Dev 10:21.

Huang EJ, Liu W, Fritzsch B, Bianchi LM, Reichardt LF, Xiang M (2001) Brn3a is a transcriptional regulator of soma size, target field innervation and axon pathfinding of inner ear sensory neurons. Development 128:2421-2432.

Huang L, Hu F, Xie X, Harder J, Fernandes K, Zeng XY, Libby R, Gan L (2014) Pou4f1 and pou4f2 are dispensable for the long-term survival of adult retinal ganglion cells in mice. PLoS One 9:e94173.

Jean P, Lopez de la Morena D, Michanski S, Jaime Tobon LM, Chakrabarti R, Picher MM, Neef J, Jung S, Gultas M, Maxeiner S, Neef A, Wichmann C, Strenzke N, Grabner C, Moser T (2018) The synaptic ribbon is critical for sound encoding at high rates and with temporal precision. Elife 7:e29275.

Jean P, Ozcete OD, Tarchini B, Moser T (2019) Intrinsic planar polarity mechanisms influence the position-dependent regulation of synapse properties in inner hair cells. Proc Natl Acad Sci U S A 116:9084-9093.

Jehn B, Chicaiza G, Martin F, Jaggi R (1994) Isolation of three novel POUdomain containing cDNA clones from lactating mouse mammary gland. Biochem Biophys Res Commun 200:156-162.

Koundakjian EJ, Appler JL, Goodrich LV (2007) Auditory neurons make stereotyped wiring decisions before maturation of their targets. J Neurosci 27:14078-14088.

Li Y, Liu H, Giffen KP, Chen L, Beisel KW, He DZZ (2018) Transcriptomes of cochlear inner and outer hair cells from adult mice. Sci Data 5:180199.

Liberman MC (1982) Single-neuron labeling in the cat auditory nerve. Science 216:1239-1241.

Liberman LD, Liberman MC (2016) Postnatal maturation of auditorynerve heterogeneity, as seen in spatial gradients of synapse morphology in the inner hair cell area. Hear Res 339:12-22.

Liberman LD, Wang H, Liberman MC (2011) Opposing gradients of ribbon size and AMPA receptor expression underlie sensitivity differences among cochlear-nerve/hair-cell synapses. J Neurosci 31:801-808.

Liberman MC (1978) Auditory-nerve response from cats raised in a lownoise chamber. J Acoust Soc Am 63:442-455.

Lumpkin EA, Collisson T, Parab P, Omer-Abdalla A, Haeberle H, Chen P, Doetzlhofer A, White P, Groves A, Segil N, Johnson JE (2003) Math1driven GFP expression in the developing nervous system of transgenic mice. Gene Expr Patterns 3:389-395.

McInturff S, Burns JC, Kelley MW (2018) Characterization of spatial and temporal development of Type I and Type II hair cells in the mouse utricle using new cell-type-specific markers. Biol Open 7:bio038083.

Malik V, Zimmer D, Jauch R (2018) Diversity among POU transcription factors in chromatin recognition and cell fate reprogramming. Cell Mol Life Sci 75:1587-1612.

Matei V, Pauley S, Kaing S, Rowitch D, Beisel KW, Morris K, Feng F, Jones K, Lee J, Fritzsch B (2005) Smaller inner ear sensory epithelia in neurog 1 null mice are related to earlier hair cell cycle exit. Dev Dyn 234:633-650.
Merchan-Perez A, Liberman MC (1996) Ultrastructural differences among afferent synapses on cochlear hair cells: correlations with spontaneous discharge rate. J Comp Neurol 371:208-221.

Meyer AC, Frank T, Khimich D, Hoch G, Riedel D, Chapochnikov NM, Yarin YM, Harke B, Hell SW, Egner A, Moser T (2009) Tuning of synapse number, structure and function in the cochlea. Nat Neurosci 12:444-453.

Michanski S, Smaluch K, Steyer AM, Chakrabarti R, Setz C, Oestreicher D, Fischer C, Mobius W, Moser T, Vogl C, Wichmann C (2019) Mapping developmental maturation of inner hair cell ribbon synapses in the apical mouse cochlea. Proc Natl Acad Sci U S A 116:6415-6424.

Morozko EL, Nishio A, Ingham NJ, Chandra R, Fitzgerald T, Martelletti E, Borck G, Wilson E, Riordan GP, Wangemann P, Forge A, Steel KP, Liddle RA, Friedman TB, Belyantseva IA (2015) ILDR1 null mice, a model of human deafness DFNB42, show structural aberrations of tricellular tight junctions and degeneration of auditory hair cells. Hum Mol Genet 24:609-624.

O’Donovan KJ, Ma K, Guo H, Wang C, Sun F, Han SB, Kim H, Wong JK, Charron J, Zou H, Son YJ, He Z, Zhong J (2014) B-RAF kinase drives developmental axon growth and promotes axon regeneration in the injured mature CNS. J Exp Med 211:801-814.

Ohlemiller KK, Echteler SM, Siegel JH (1991) Factors that influence rateversus-intensity relations in single cochlear nerve fibers of the gerbil. J Acoust Soc Am 90:274-287.

Ohn TL, Rutherford MA, Jing Z, Jung S, Duque-Afonso CJ, Hoch G, Picher MM, Scharinger A, Strenzke N, Moser T (2016) Hair cells use active zones with different voltage dependence of $\mathrm{Ca} 2+$ influx to decompose sounds into complementary neural codes. Proc Natl Acad Sci U S A 113:E4716-E4725.

Pangrsic T, Singer JH, Koschak A (2018) Voltage-gated calcium channels: key players in sensory coding in the retina and the inner ear. Physiol Rev 98:2063-2096.

Petitpré C, Wu H, Sharma A, Tokarska A, Fontanet P, Wang Y, Helmbacher F, Yackle K, Silberberg G, Hadjab S, Lallemend F (2018) Neuronal heterogeneity and stereotyped connectivity in the auditory afferent system. Nat Commun 9:3691.

Picelli S, Faridani OR, Bjorklund AK, Winberg G, Sagasser S, Sandberg R (2014) Full-length RNA-seq from single cells using Smart-seq2. Nat Protoc 9:171-181.

Platzer J, Engel J, Schrott-Fischer A, Stephan K, Bova S, Chen H, Zheng H, Striessnig J (2000) Congenital deafness and sinoatrial node dysfunction in mice lacking class D L-type $\mathrm{Ca}^{2+}$ channels. Cell 102:89-97.

Sajgo S, Ghinia MG, Brooks M, Kretschmer F, Chuang K, Hiriyanna S, Wu Z, Popescu O, Badea TC (2017) Molecular codes for cell type specification in Brn3 retinal ganglion cells. Proc Natl Acad Sci U S A 114:E3974-E3983.

Shrestha BR, Chia C, Wu L, Kujawa SG, Liberman MC, Goodrich LV (2018) Sensory neuron diversity in the inner ear is shaped by activity. Cell 174:1229-1246.e17.

Sun S, Babola T, Pregernig G, So KS, Nguyen M, Su SM, Palermo AT, Bergles DE, Burns JC, Müller U (2018) Hair cell mechanotransduction regulates spontaneous activity and spiral ganglion subtype specification in the auditory system. Cell 174:1247-1263.e15.

Taberner AM, Liberman MC (2005) Response properties of single auditory nerve fibers in the mouse. J Neurophysiol 93:557-569.

Tantin D (2013) Oct transcription factors in development and stem cells: insights and mechanisms. Development 140:2857-2866.

Winter IM, Robertson D, Yates GK (1990) Diversity of characteristic frequency rate-intensity functions in guinea pig auditory nerve fibres. Hear Res 45:191-202.

Wiwatpanit T, Lorenzen SM, Cantú JA, Foo CZ, Hogan AK, Marquez F, Clancy JC, Schipma MJ, Cheatham MA, Duggan A, García-Añoveros J (2018) Trans-differentiation of outer hair cells into inner hair cells in the absence of INSM1. Nature 563:691-695.

Wong AB, Rutherford MA, Gabrielaitis M, Pangrsic T, Gottfert F, Frank T, Michanski S, Hell S, Wolf F, Wichmann C, Moser T (2014) Developmental refinement of hair cell synapses tightens the coupling of $\mathrm{Ca}^{2+}$ influx to exocytosis. EMBO J 33:247-264.

Xiang M, Gan L, Zhou L, Klein WH, Nathans J (1996) Targeted deletion of the mouse POU domain gene brn-3a causes selective loss of neurons in the brainstem and trigeminal ganglion, uncoordinated limb movement, and impaired suckling. Proc Natl Acad Sci U S A 93:11950-11955.

Zenisek D, Horst NK, Merrifield C, Sterling P, Matthews G (2004) Visualizing synaptic ribbons in the living cell. J Neurosci 24:9752-9759. 